\title{
Addressing critical success factors for improving concurrent emergency management: lessons learned from the COVID-19 pandemic
}

\author{
Aliza Sharmin ${ }^{1} \cdot$ Md. Adib Rahman $^{1} \cdot$ Sayem Ahmed $^{1}$ (D) $\cdot$ Syed Mithun Ali $^{2}$ (C)
}

Accepted: 15 November 2021

(c) The Author(s), under exclusive licence to Springer Science+Business Media, LLC, part of Springer Nature 2021

\begin{abstract}
The world is witnessing a difficult time trying to circumscribe the spread of COVID-19 pandemic. The situation has become even more challenging as several natural disasters and emergencies coincided with this pandemic and created a situation of concurrent emergency. Effectively managing concurrent emergencies are extremely challenging. Only by utilizing and applying the knowledge gathered while combating a real-life concurrent emergency, one can further be prepared to face such emergencies. Hence, this study intends to identify the critical success factors (CSFs) having a major role in effective management of concurrent emergencies and evaluate the indispensable links among the factors. Twelve CSFs are identified from Pareto analysis, for which feedback from 46 experts involved in the management of emergencies is utilized. In addition, the revised rough-decision making trial and evaluation laboratory (rough-DEMATEL) approach is suggested to analyze the indispensable links among the CSFs and further, these factors are ranked based on the average vector length. The recent case of concurrent emergency in Bangladesh- floods amid a pandemic is considered to establish the applicability of this method. The findings of this research reveal that to handle concurrent emergencies 'Incremental improvement of proactive measures', 'Resilient supply chain and logistics network', and 'Government leadership and military cooperation' are the most critical factors to concurrent emergency management (CEM). These CSFs play a major role in ensuring the effectiveness of CEM. Thus, this study can be a building block in developing an effective CEM plan for the policymakers, managers, and practitioners.
\end{abstract}

$\bowtie \quad$ Syed Mithun Ali

mithun@ipe.buet.ac.bd; syed.mithun@gmail.com

Aliza Sharmin
aliza.ipe@aust.edu

Md. Adib Rahman

adib.ipe@aust.edu

Sayem Ahmed

sayem.ipe@aust.edu

1 Department of Mechanical and Production Engineering, Ahsanullah University of Science and Technology, Dhaka 1208, Bangladesh

2 Department of Industrial and Production Engineering, Bangladesh University of Engineering and Technology, Dhaka 1000, Bangladesh 
Keywords Concurrent emergency management · Critical success factors · COVID-19 . Disaster risk · Floods · Revised rough DEMATEL

\section{Introduction}

With over 107 million confirmed COVID-19 cases and 1.45 million deaths caused by it around the world at the time of writing, the outbreak of this pandemic is still on the rise (COVID-19 Map - Johns Hopkins Coronavirus Resource Center, 2021). The pandemic alone has substantially disrupted human lives, economies, relief and healthcare systems (Cao et al., 2020; Sasangohar et al., 2020). On top of this, numerous climate hazards took place during this pandemic, which have exacerbated the situation and unprecedentedly tested the existing infrastructure of concurrent emergency management (CEM) unveiling incompetency of the policies that needs immediate amendment for minimizing loss of lives. The occurrence of a two or more emergencies simultaneously creates a multi-hazard event or a concurrent emergency situation (Peters \& Lovell, 2020). This article aims to address critical success factors for such a concurrent emergency situation.

COVID-19 is referred to as a disaster in several studies (Aburas \& Alshammari, 2020; Gersons et al., 2020; Sakurai \& Chughtai, 2020). Also, World Health Organization (2019) stated that disasters comprise "infectious disease outbreaks, natural hazards, conflicts, unsafe food and water, chemical and radiation incidents, building collapses, transport incidents, lack of water and power supply, air pollution, antimicrobial resistance, the effects of climate change, and other sources of risk". The U.S. faced a difficult time battling the COVID-19 along with wildfires, tornadoes, and hurricanes; as emergency management (EM) was solely focused on one event at a time (Borowski et al., 2021). On March 20, 2020, a massive earthquake shook Croatia and converged with the ongoing covid crisis jeopardizing the lives of vulnerable people (Rok et al., 2020). On May 20, 2020, India and Bangladesh were hit by cyclone Amphan, which is the most severe storm since 1999 in this region. The cyclone severely flooded the coastal areas of Bangladesh causing unimaginable sufferings and destruction. Occurrence of these difficult situations highlighted limitations of the existing system and the necessity of preparation for effectively handling such concurrent emergencies in future (Ebrahim et al., 2020). Climate change presumably will increase the frequency and severity of dual disasters and surely this pandemic will not be the last (Phillips et al., 2020). To ensure proper management of such concurrent emergencies, it is essential to determine and evaluate the success factors and formulate a plan that accommodates those identified critical factors (Aschemann-Witzel et al., 2017). Critical success factors (CSFs) are those aspects that need to function properly for ensuring the success of the entire system (Dinter, 2013). The performance and success of CEM are dependent on these CSFs and identification of these factors is crucial for combating such situations successfully in the future. Identifying CSFs means finding out the factors having the most prominent impact on the CEM system, which helps the managers put greater stress on them and improve the system in a stepwise way (Bai \& Sarkis, 2013). As CEM has resource constraints, it is demanding for practitioners and decision makers to work on all the influencing factors simultaneously. Prioritization of these influential factors are necessary as while some factors contribute more, others do comparatively less and some of them even work as a catalyst (Li et al., 2014; Gunessee et al., 2018). Thus, improvement for these prioritized CSFs can significantly increase the efficiency of CEM. 
A review of literature reveals an absence of studies that have addressed the issues of identifying the CSFs for concurrent emergencies. Ishiwatari et al. (2020) highlighted the difficulties of managing concurrent disasters, and proposed some policies and approaches to managing such situations but did not identify the factors crucial for an efficient CEM. There are few studies that explored the CSFs of EM (Ding \& Liu, 2018; Han \& Deng, 2018a, 2018b; Li et al., 2014; Zhou et al., 2011, 2017). Some of these studies ranked the CSFs and classified them to influenced and influential factors, which significantly contributed to enhance the effectiveness of EM by facilitating informed managerial decision making. However, none of these studies addressed concurrent emergencies. Also, the methods utilized for existing studies require vast amount of data and struggle to handle information loss in case of emergency situations. Moreover, there is a lack of studies on the CSFs of CEM, interdependencies of CSFs for CEM and their indispensable links. Thus, it is necessary to identify and prioritize the CSFs for concurrent emergencies and discover the causal interrelations among the CSFs. Hence, the following questions are addressed by this research:

RQ1: What are the CSFs for tackling CEM? (see Sect. 3)

RQ2: How do the CSFs influence the effective CEM and how are they dependent? (see Sect. 4)

RQ3: What are the managerial implications of this research for CEM? (see Sect. 6)

To answer the above research questions, in this research, an integrated framework is developed to identify and analyze the CSFs of CEM utilizing decision making trial and evaluation laboratory (DEMATEL) as well as revised rough set theory. DEMATEL is more advantageous over other multi-criteria decision-making (MCDM) techniques because it can examine the relationships among factors and graphically portray the multifaceted causal interrelations among the factors by means of cause-effect diagram (Moktadir et al., 2018). Generally, DEMATEL approach is superior to analytical hierarchy process (AHP) and technique for order preference by similarity to ideal solution (TOPSIS) for investigating dependent factors (Venkatesh et al., 2017). DEMATEL is also preferred to interpretive structural modeling (ISM) approach as ISM provides weak interpretation of structural relationship and not the complete degree of influence of factors (Banik et al., 2020). However, only DEMATEL method is not well equipped to address the potential vagueness and uncertainty in the data (Song \& Cao, 2017). To address this challenge, this paper applied revised rough DEMATEL method, which brings the strength of DEMATEL in investigating the cause-effect interdependencies among CSFs with the merit of rough set theory to cope with the subjectivity of inputs while preventing assessment information loss (Ahmed et al., 2021). Rough set theory provides a crisp set approximation by stating lower and upper approximations of target set. Lower approximations are conformist, consisting of only the elements that are members of the set, while upper approximations are liberal, consisting of all the possible elements regardless of being members of the target set (Khoo et al., 1999). Moreover, this theory overcomes subjectivity of data by utilizing rough number (RN) and intervals, necessitating minimum additional data. While handling emergencies, obtaining enough information to assess and handle the situation is always a challenge. Hence, the incorporation of rough set theory with DEMATEL is appropriate to manage emergencies (Liu \& Ming, 2019). The proposed method also provides more reliable results requiring much less prior information. The relations between CSFs of CEM are constructed in a systematic way using a causal diagram where the CSFs are divided into cause and effect groups. Causal diagram helps decisionmakers to understand the complicated associations easily within the CSFs. In this respect, this method is appropriate to evaluate the indispensable links among the CSFs of CEM due to the inherent uncertainty of emergency situations and lack of information to access and 
analyze. Therefore, the proposed framework was applied to the recent case of concurrent emergency in Bangladesh, floods amid COVID-19 and the interactions among the CSFs are analyzed for ensuring effective management of concurrent emergencies.

This paper is organized as follows: Sect. 2 reviews few of the prior literature of EM. The methodology of this study is discussed in Sect. 3. Section 4 presents a discussion on the obtained results and sensitivity analysis. In Sect. 5, a validation of the proposed method is shown. The theoretical and practical implications of this research are discussed in Sect. 6. Finally, Sect. 7 concludes this paper.

\section{Literature review}

The occurrence of a two or more emergencies simultaneously creates a multi-hazard event or a concurrent emergency situation (Peters \& Lovell, 2020). Regions facing extreme-weather induced disasters are more likely to face a situation like this. COVID-19 further increases the likelihood of concurrent emergency situations and occurrence of a disaster can escalate the COVID-19 infection rate (Simonovic, 2021). Assessment of the concurrent emergencies challenges and the compound risks they pose is critical to provide further guidance for addressing these unprecedented situations effectively. Taking notes from the management of real concurrent emergencies and refine the knowledge with the insightful opinions of experts can yield a new approach, which is needed to deal with these concurrent emergency situations. Proactive measures are as vital as resilience in case of managing any large or small scale emergency (Doan \& Shaw, 2018). The responsible actors of CEM need be equipped with the information of elements which dictates the success of the whole management system to maneuver the actions they must take. Current practices in handling compound hazards is typically reactive and fixated on one emergency at a time rather than both simultaneously (Su et al., 2016). Thus, this demands a new tactic while dealing with threat and effect of concurrent emergencies.

EM has drawn more attention in recent times due to the increase of natural and man-made disasters (Behl \& Dutta, 2019; Dubey et al., 2019a, 2019b). It is predicted that climate change will further upsurge disaster occurrence taking a toll on human lives (Fuli et al., 2020; Liu et al., 2019). For alleviating human suffering and improving the operational effectiveness of EM, it is essential to determine the crucial factors or CSFs having the highest impact on the effectiveness of the whole system. The decision-makers can then give more attention to these crucial factors or CSFs to enhance EM performance (Zhou et al., 2011). Meibodi and Monavvarian (2010) considered CSF to be readily evident activities that management must undertake to achieve its objectives. The extensive application of CSF in management practices is justified by the ability of these factors to drive and ensure the improvement of any system.

The CSFs of EM were explored in some previous literature. Oloruntoba (2010) identified some key emergency relief chain (ERC) success factors of the Cyclone Larry on the basis of document investigation and semi-structured discussions with emergency managers affiliated with cyclone relief management processes. Zhou et al. (2011) considered twenty CSFs of EM and further visualized the interrelationships among CSFs using fuzzy DEMATEL method. The result of his research demonstrates five CSFs that influence the effectiveness of emergency management the most. Li et al. (2014) applied the evidential DEMATEL method to prioritize the CSFs of EM. Yadav and Barve (2015) utilized MCDM techniques such as ISM and MICMAC (Matriced' Impacts Croisés Multiplication Appliquée á un Classement) 
Table 1 Existing literature on CSFs for Emergency Management and Humanitarian Supply Chain

\begin{tabular}{ll}
\hline Topic & Sources \\
\hline Emergency management & Zhou et al. (2011), Li et al. (2014), Zhou et al. (2017), Ding and Liu, \\
& (2018), Han and Deng (2018a), Han and Deng (2018b), Liu et al. (2019), \\
& Mao et al. (2019), Edjossan-Sossou et al. (2020), Rivera et al. (2020), \\
& Sardjono et al. (2020) \\
Humanitarian supply chain & Oloruntoba (2010), Yadav and Barve (2015), Celik and Gumus (2016), \\
& Behl et al. (2019) \\
\hline
\end{tabular}

to evaluate the CSFs in the preparedness and response phase of humanitarian supply chain (HSC). Celik and Taskin Gumus (2016) worked with the same phases of HSC as Yadav and Barve (2015), but utilized a hybrid approach comprising interval type-2 fuzzy sets, AHP and PROMETHEE. Later, Zhou et al. (2017) considered the same ten CSFs of emergency management as Li et al. (2014) then applied D-DEMATEL to analyze the interrelations of the CSFs of emergency management. Han and Deng (2018a) proposed a hybrid intelligent model for assessing the CSFs of high-risk emergency systems. They combined DEMATEL, fuzzy cognitive map (FCM) and Dempster-Shafer evidence theory to fuse technical, economic, political, and social attributes of emergency systems. Han and Deng (2018b) implemented an enhanced fuzzy evidential DEMATEL method to determine the CSFs of EM where Ding and Liu (2018) utilized a 2-dimension uncertain linguistic DEMATEL method for doing the same. Liu et al. (2019) implemented a combined method consisting of fuzzy cognitive map (FCM) and Pearson's product-moment correlation coefficient to define the CSFs in EM. Behl et al. (2019) adopted a grey DEMATEL approach to explore the CSFs of HSC. Sardjono et al. (2020) used two-factor analysis method to measure the CSFs of natural disaster mitigation. Edjossan-Sossou et al. (2020) attempted to select and evaluate sustainable risk management strategies using fuzzy AHP and fuzzy PROMETHEE to identify the most sustainable strategy under uncertainty. Mao et al., (2019) and Rivera et al., (2020) focused on capturing the challenges and risk factors of emergency and disaster risk management to promote the efficiency and effectiveness of management practices. The literature on CSFs is summarized in Table 1 .

Although there is reasonable literature on EM, there are only limited works on the specific area of CEM; for instance, Davis (2014) focused on how the determining factors of concurrent disasters interact and merge. Su et al. (2016) addressed compound crisis resource allocation issues in case of concurrent incidents in natural disasters. Recently, Peters and Lovell (2020) discussed the multiple disaster displacement issues and emphasized the necessity of understanding and addressing the underlying factors to yield more durable solutions. However, none of them considered the crucial issue of identification and evaluation of CSFs of CEM. In most of the previous studies where CSFs are identified in the field of EM utilizing experts' evaluation, essential issues such as limited information availability, handling linguistic assessment ambiguity while fusing multiple experts' evaluation were not properly addressed.

Concurrent emergencies preparedness actions cannot be generalized with other emergencies even though some commonalities exist. COVID-19 outbreak along with other disasters created a severe havoc, which is a major wake-up call in this regard. Cyclone Amphan flooded the coastal areas of Bangladesh while COVID-19 infection rate was rising alarmingly in the country. This further intensified the sufferings of people and called for multifaceted measures 
and prompt decisions to circumscribe the losses. People of coastal areas needed to be immediately evacuated and sent to shelters, but in this instance the shelters could not be overcrowded as ensuring physical distancing is the only way to prevent the spread of virus. The concerned authorities fought two disasters at once and somehow tackled this double blow. However, this highlighted the need to analyze the steps taken to combat such concurrent emergencies to further implement them as even slightest mismanagement can yield catastrophic outcomes. Taking this issue into consideration, this article utilizes the experience from one concurrent emergency (flood during COVID-19) and identifies what factors played a critical role for successfully handling the situation. Thus, a revised rough DEMATEL method is utilized to analyze indispensable links between CSFs in this study for addressing these issues. This technique further extends the rough theory by incorporating average vector length (AVL). AVL is a more feasible operator in comparison with single vector (Dalalah et al., 2011), CFCS (converting fuzzy data into crisp scores) (Rajesh \& Ravi, 2015) because it eliminates the need for additional de-roughness and determines the rough-relation and rough-prominence value to prioritize and evaluate the CSFs. Rough set has the strength to manipulate the interpersonal ambiguity by incorporating $\mathrm{RN}$ and combining numerous judgements into a flexible rough intervals instead of membership function without requiring supplementary information (Khoo et al., 1999). Previously, Liu and Ming (2019) utilized this method for requirement evaluation of smart industrial product-service system (PSS) of systems. Ahmed et al. (2021) evaluated the of flexible tactics for education sector management amid COVID-19 crisis utilizing this method.

To the best of our knowledge, the issues of CEM and identification of CSFs to ensure its effectiveness have not been addressed yet. This research is the first to determine the CSFs of CEM and reveal the influential relationships and indispensable links between and among the CSFs utilizing a unique methodology which has not been yet applied to any such context. Therefore, the focus on identifying the CSFs of CEM along with the indispensable links among them is novel. This research contribution includes:

i. Identifying the CSFs of CEM utilizing both experts' inputs and literature review.

ii. Prioritizing and assessing the factors and their interrelations applying a revised rough DEMATEL framework.

iii. Investigating the interrelationships among the CSFs and proposing both theory and practical implications relating to effective CEM.

iv. Providing valuable insights and extra flexibility to the policymakers in case of formulating policies and measures under uncertain situations while ensuring the effectiveness of CEM.

\section{Context and methodology}

Along with the challenge of curving down COVID-19 infected rate, many countries have struck with another disaster creating a situation of concurrence emergency (Adhikari et al., 2020; Pankow et al., 2021; Rok et al., 2020). The COVID-19 virus was confirmed to have spread to Bangladesh in March 2020. The situation soon escalated and till May 15, 2020, there were 20,065 confirmed COVID cases with a total of 298 deaths (Worldometer, 2021). The situation got even worse when on May 20, 2020, Bangladesh got hit by cyclone Amphan and created a concurrent emergency. Surviving two such big disasters simultaneously took a toll on the disaster-stricken people. This particular phenomenon highlighted the importance of preparation for such concurrent emergencies and emphasized the necessity of effective CEM. 
As it is challenging to improve CEM in all aspects, a more efficient way should be opted to focus on the most crucial factors having the most vital influence on the system. Thus, this study prioritizes the CSFs of CEM and analyzes the interrelationships between them, proposing a quantitative approach that supports decision-making. For this a methodology consisting of the literature review, Pareto analysis, and revised rough DEMATEL is utilized to explore the CSFs of CEM investigating the interrelationships among the CSFs inputting the practitioners' view and proposing both theory and practical implications relating to effective CEM. The proposed methodology is further validated through both comparative and sensitivity analysis. For this, a Pareto-based revised rough DEMATEL approach is utilized. Figure 1 represents the key steps of the proposed research framework.

\subsection{Identification of the CSFs of CEM}

In previous works, CSFs are primarily identified through literature review, expert interview, or case study. This research used a combination of literature review and survey questionnaire which was administrated online to identify the influential factors of CEM.

The survey questionnaire was first administered to the individuals involved in the management of the concurrent disaster that occurred in Bangladesh in May 2020. The respondents were selected using purposive snowball sampling which accommodates both deliberate choice of respondents who are well-informed with the phenomenon of interest and utilizes the knowledge of insiders to locate relevant people to contribute to the study (Etikan \& Bala, 2017; Salim et al., 2019). This method can also overcome the challenges of a low response rate. A web-based digital survey was conducted between October 2020 and January 2021. The respondents were assured that their detailed suggestions would be kept confidential. Initially, a questionnaire (see "Appendix B") was distributed among 45 experts' individuals related to the emergency management of the concurrent disaster in Bangladesh. 32 survey replies were received (response rate $71.11 \%$ ), and further, they forwarded the questionnaire to 19 others relevant to the field concerned. Finally, a total of 46 surveys were accepted out of 51 responses $(9.80 \%$ refused for incomplete information) for the final analysis. The questionnaire included a Yes/No-based list of CSFs along with a 5- point Likert scale to assess the significance of the factors. The profile of these experts is detailed in Table 2.

In this study, Pareto analysis was performed to identify the crucial factors by separating the 'vital few' from the 'trivial many' using the 80/20 rule (Craft \& Leake, 2002). Previous research works in fields such as food safety (Fotopoulos et al., 2011), supply chain management (SCM) (Talib et al., 2015), green SCM (Kaur et al., 2019), and education (Ahmed et al., 2021) have applied Pareto analysis to determine the most crucial factors having the largest impact.

Since there was no such literature related to the CSFs of CEM, the closest related works in the field of EM are considered to use in the questionnaire (see "Appendix B"). 15 CSFs of EM obtained from previous literature are shown in Table 3.

From the initial 15 CSFs demonstrated in Table 3, eight were identified as the CSFs of CEM through Pareto analysis with slight modification by the experts. The result of Pareto analysis is demonstrated in Table 11 ("Appendix A") and Fig. 2. According to the expert inputs 'Improvement of proactive measures to handle concurrent emergencies', 'Psychological support', 'Clearly stated instructions and early caution about potential dangers' and 'Availability of need and resource assessment tools' were modified to 'Incremental improvement of proactive measures', 'Short and long term psychological support', 'Clearly stated instructions, 


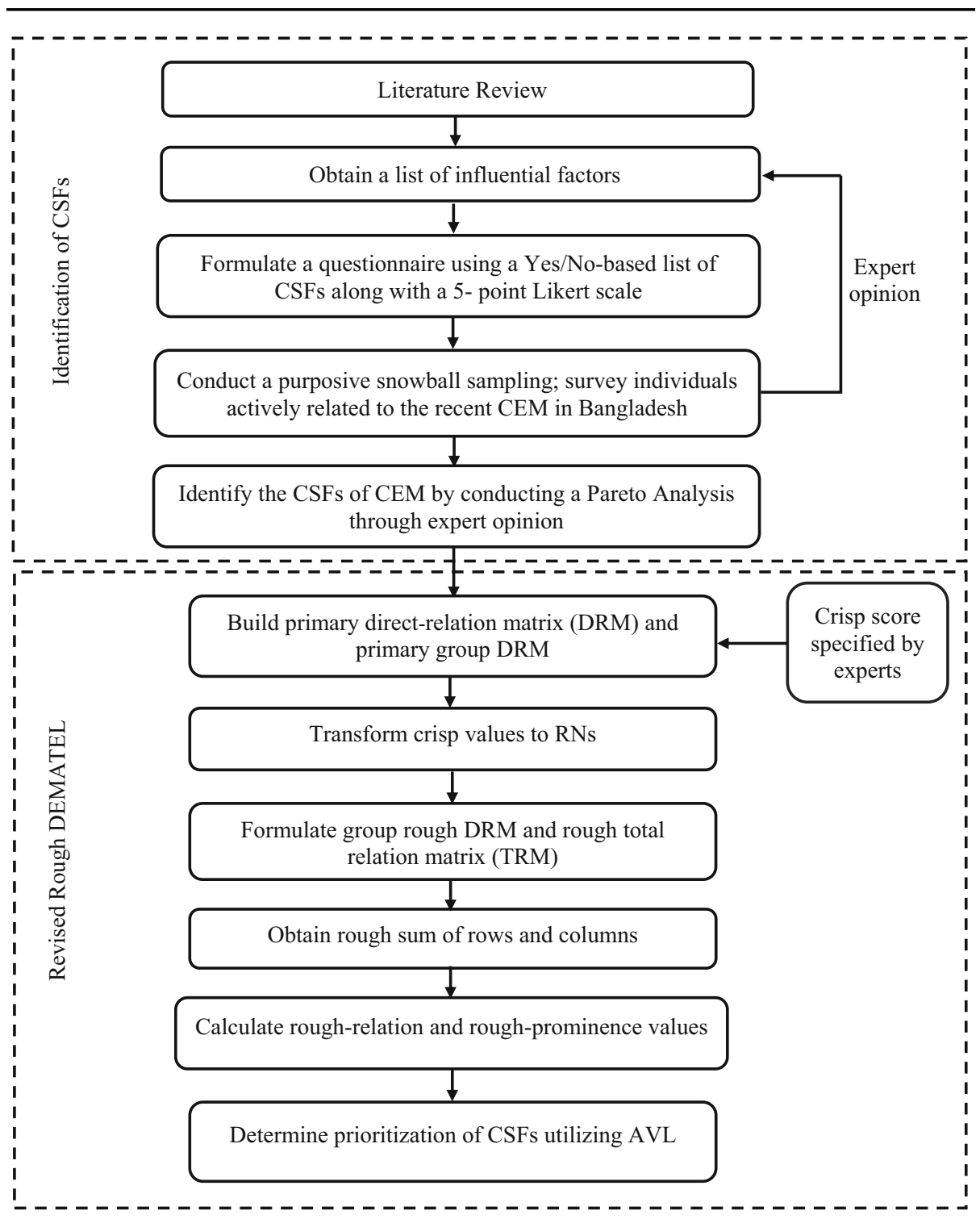

Fig. 1 The applied research framework

quick feedback and early warning' and 'Availability of effective need and resource assessment tools' respectively. The average weights given by experts were considered for selecting the 8 most CSFs. Further, 4 CSFs were directly added (i.e., corporate social responsibility (CSR) efforts of organizations, Resilient supply chain and logistics network, Prioritization of the preparedness phase action, Individual and community awareness), which were suggested by the experts based on their experience of the recent concurrent emergency of Bangladesh. So, total 12 CSFs were identified as demonstrated in Table 4. 
Table 2 Expert profiles

\begin{tabular}{llll}
\hline Variable & Number of respondents & $\begin{array}{l}\text { Percentage of } \\
\text { respondents }\end{array}$ & \\
\hline Years of relevant experience & $0-10$ years & 10 & 21.74 \\
& $10-20$ years & 15 & 32.61 \\
Role / Job position & 20-30 years & 21 & 45.65 \\
& Top level manager & 13 & 28.26 \\
& Middle level manager & 18 & 39.13 \\
& Policymaker & 09 & 19.57 \\
& Academic & 06 & 13.04 \\
\hline
\end{tabular}

Table 3 A list of CSFs from previous literature on Emergency Management

\begin{tabular}{|c|c|c|}
\hline Sl. No. & CSFs & References \\
\hline 1 & $\begin{array}{l}\text { Periodic arrangement of disaster exercise } \\
\text { simulation }\end{array}$ & $\begin{array}{l}\text { Zhou et al. (2011), Zhou et al. (2017), } \\
\text { Chan (2020) }\end{array}$ \\
\hline 2 & $\begin{array}{l}\text { Empowerment of emergency response management } \\
\text { team }\end{array}$ & Chan (2020) \\
\hline 3 & Reconstruction and staff comforting & Zhou et al. (2011) \\
\hline 4 & Government leadership and military cooperation & $\begin{array}{l}\text { Zhou et al. (2011), Ishiwatari et al. } \\
\text { (2020), Zhou et al. (2017) }\end{array}$ \\
\hline 5 & Prevent corruption in aid distribution & Zhou et al. (2017) \\
\hline 6 & $\begin{array}{l}\text { Improvement of proactive measures to handle } \\
\text { concurrent emergencies }\end{array}$ & Zhou et al. (2011) \\
\hline 7 & $\begin{array}{l}\text { Evaluation of the efficiency and effectiveness of } \\
\text { management system }\end{array}$ & Zhou et al. (2011) \\
\hline 8 & Psychological support & Chan (2020) \\
\hline 9 & $\begin{array}{l}\text { Explicit procedure for reporting and submitting } \\
\text { information }\end{array}$ & Zhou et al. (2011) \\
\hline 10 & $\begin{array}{l}\text { Minimum response time to initiate the emergency } \\
\text { plan }\end{array}$ & Zhou et al. (2011) \\
\hline 11 & $\begin{array}{l}\text { Clearly stated instructions and early caution about } \\
\text { potential dangers }\end{array}$ & $\begin{array}{l}\text { Zhou et al. (2011), Zhou et al. (2017), } \\
\text { Ishiwatari et al. (2020) }\end{array}$ \\
\hline 12 & $\begin{array}{l}\text { Appropriate emergency response strategy and } \\
\text { regulations }\end{array}$ & Zhou et al. (2017), Chan (2020) \\
\hline 13 & Availability of need and resource assessment tools & Zhou et al. (2011), Zhou et al. (2017) \\
\hline 14 & Individual and community awareness & Ishiwatari et al. (2020) \\
\hline 15 & $\begin{array}{l}\text { Awareness of responsibilities and rational } \\
\text { organizational structure }\end{array}$ & Zhou et al. (2011), Zhou et al. (2017) \\
\hline
\end{tabular}




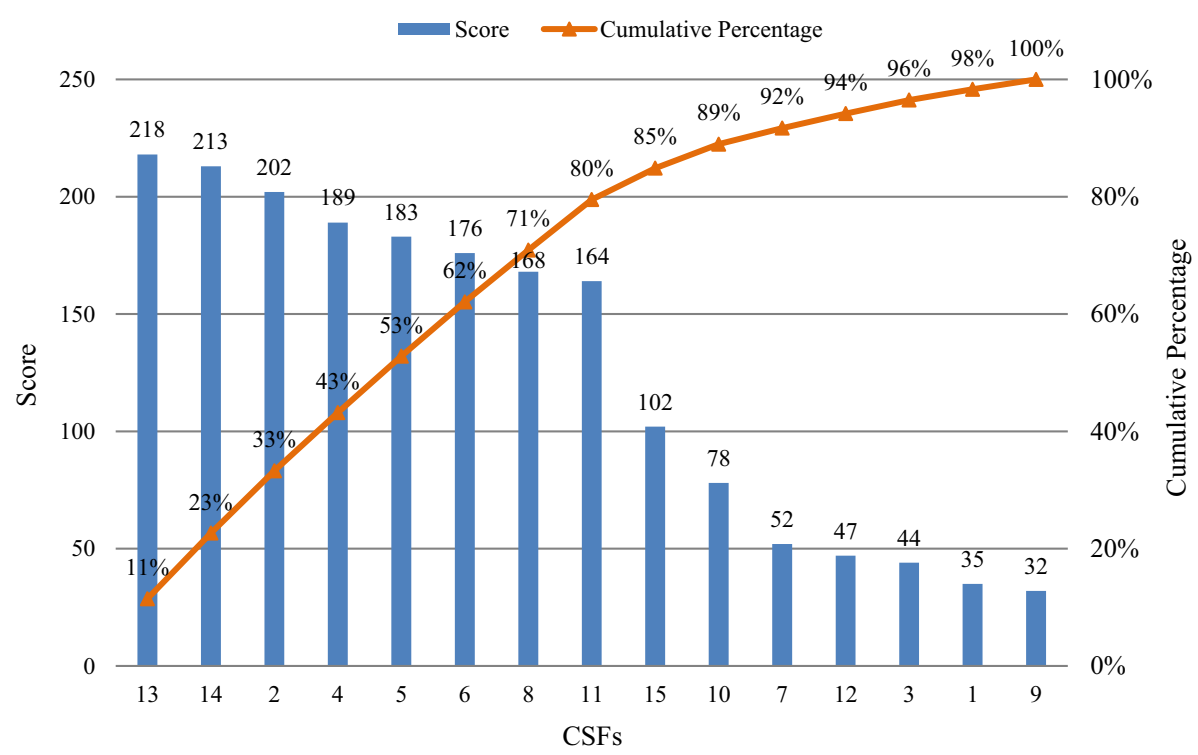

Fig. 2 Pareto chart of CSFs

\subsection{The proposed method for CSF analysis: revised rough DEMATEL}

Revised rough DEMATEL method is suggested for prioritizing the CSFs and analyzing the indispensable links among the 12 critical factors obtained from the Pareto analysis. The DEMATEL method has been successfully extended in the proposed method by incorporating a rough aggregation approach that can effectively manipulate imprecise information. It also considers the complex interactions between different factors and better captures information by using the RN. However, most literature implements fuzzy logic, though fuzzy approach demands additional prior information (e.g., fuzzy membership and non-membership function) compared to the revised rough-DEMATEL (Song \& Cao, 2017). Hence, this method can be utilized to attain a more accurate analysis. Steps of this method are given below (Dalalah et al., 2011; Song \& Sakao, 2018; Zhai et al., 2009).

Step 1: Primary DRM and primary group DRM formulation

A primary DRM $\left[k_{x y}^{r}\right]_{s \times s}, r=1,2, \ldots, e$ is specified by $r^{t h}$ expert, $k_{x y}^{r}$ represents the degree of influence of $x^{\text {th }}$ CSF with regard to $y^{t h}$ CSF stated by $r^{t h}$ expert. The DRM amongst factors is below:

$$
D_{r}=\left[\begin{array}{cccc}
1 & k_{12}^{r} & \cdots & k_{1 s}^{r} \\
k_{21}^{r} & 1 & \cdots & k_{2 s}^{r} \\
\vdots & \vdots & \ddots & \vdots \\
k_{s 1}^{r} & k_{s 2}^{r} & \cdots & 1
\end{array}\right] ; x, \quad y=1,2, \ldots, s
$$

Here, number of experts $=e$, and number of CSFs $=s$.

Further, $e$ experts give crisp scores to the CSFs for pair-wise comparisons of the CSFs. The ratings are set following this order (weak influence $=1$, moderate influence $=2$, strong influence $=3$, extremely strong influence $=4$ ). 
Table 4 Identified CSFs for CEM

\begin{tabular}{ll}
\hline Code & CSFs \\
\hline CSF1 & $\begin{array}{c}\text { Empowerment of emergency response } \\
\text { management team }\end{array}$
\end{tabular}

CSF2 Government leadership and military cooperation

CSF3 Prevent corruption in aid distribution

CSF4 CSR efforts of organizations

CSF5 Resilient supply chain and logistics network

CSF6 Prioritization of the preparedness phase actions

CSF7 Incremental improvement of proactive measures

CSF8 Short and long term psychological support

CSF9 Clearly stated instructions, quick feedback and early warning

CSF10 Availability of effective need and resource assessment tools

CSF11 Adequate and available financial resources

CSF12 Individual and community awareness
Descriptions

A cohesive, well-developed emergency response team is essential for quick identification and mobilization of the affected population and preventing adverse incidents and lives lost

Effective leadership from the government, along with armed forces support, before, during and after concurrent emergencies can expedite the disaster recovery process

CEM is vulnerable to corruption and fraud as it is carried out under immense pressure and difficult circumstances

Non-governmental organizations (NGOs) and businesses can play a vital role in CEM

For avoiding any discontinuation of aid supply or evacuation measures, supply chain and logistics networks need to become more resilient

For ensuring quick response capacity and loss reduction, pre-disaster management is more impactful than post-disaster analysis

Existing robust plans might not be effective for the changed reality. Effective integration of two emergency response plans is necessary

Personal or direct assistance as psychological intervention and structural assistance work as a prerequisite of psychosocial rehabilitation

Clear and continuous communication is the key to combating concurrent emergencies

There needs to be a constant assessment of medical assistance and relief need and the available resources to fulfill the need

Response and recovery operations require enormous financial investments and for that government must ensure adequate funds in this sector

It is essential to build awareness within the community and enhance the capacities of local organizations for disaster management by providing necessary information, monetary and technical support 
The primary group DRM is expressed by following Eq. (2).

$$
\tilde{P}=\left[\tilde{k}_{x y}\right]_{s \times s}=\left[\begin{array}{cccc}
1 & \tilde{k}_{12} & \cdots & \tilde{k}_{1 s} \\
\tilde{k}_{21} & 1 & \cdots & \tilde{k}_{2 s} \\
\vdots & \vdots & \ddots & \vdots \\
\tilde{k}_{s 1} & \tilde{k}_{s 2} & \cdots & 1
\end{array}\right]
$$

Here, $\tilde{k}_{x y}=\left\{k_{x y}^{1}, k_{x y}^{2}, \ldots, k_{x y}^{r}, \ldots, k_{x y}^{e}\right\}$

\section{Step 2. Group rough DRM construction}

A expert opinion set of $e$ classes, $E=\left\{k_{x y}^{1}, k_{x y}^{2}, \ldots, k_{x y}^{r}, \ldots, k_{x y}^{e}\right\}$, is considered in an order of $k_{x y}^{1}<k_{x y}^{2}<\ldots .<k_{x y}^{r}<\ldots<k_{x y}^{e}$ where all entities are included in universe $U$ and there is an arbitrary entity A of $U$. Lower and higher estimation of $k_{x y}^{r}$ can then be defined as:

Lower estimation:

$$
\underline{\operatorname{Estim}}\left(k_{x y}^{r}\right)=\mathrm{U}\left\{\mathrm{A} \in \mathrm{U} / \mathrm{E}(\mathrm{A}) \leq k_{x y}^{r}\right\}
$$

Higher estimation:

$$
\overline{\operatorname{Estim}}\left(k_{x y}^{r}\right)=\mathrm{U}\left\{\mathrm{A} \in \mathrm{U} / \mathrm{E}(\mathrm{A}) \geq k_{x y}^{r}\right\}
$$

Here, $k_{x y}^{r}$ is demonstrated as $\mathrm{RN}$ and is given by lower limit $\underline{l}\left(k_{x y}^{r}\right)$ and higher limit $\overline{1}\left(k_{x y}^{r}\right) \cdot G_{x y}$ and $O_{x y L}$ are the elements of lower approximation of $k_{x y}^{r}$ and total entities counted in the lower approximation of $k_{x y}^{r}$, respectively. Similarly, $J_{x y}$ and $O_{x y H}$ are for higher approximation of $k_{x y}^{r}$. The equations are given by:

$$
\begin{aligned}
& \underline{l}\left(k_{x y}^{r}\right)=\frac{\sum_{e=1}^{O_{x y L}} G_{x y}}{O_{x y L}} \\
& \underline{l}\left(k_{x y}^{r}\right)=\frac{\sum_{e=1}^{O_{x y U}} J_{x y}}{O_{x y H}}
\end{aligned}
$$

All the crisp judgments on CSFs can be converted into RN, N $\left(\tilde{k}_{x y}\right)$ following Eqs. (3-6),

$$
N\left(\tilde{k}_{x y}\right)=\left[\tilde{k}_{x y}^{r L}, \tilde{k}_{x y}^{r H}\right]=\left\{\left[\tilde{k}_{x y}^{1 L}, \tilde{k}_{x y}^{1 H}\right]\left[\tilde{k}_{x y}^{2 L}, \tilde{k}_{x y}^{2 H}\right] \ldots\left[\tilde{k}_{x y}^{r L}, \tilde{k}_{x y}^{r H}\right] \ldots\left[\tilde{k}_{x y}^{e L}, \tilde{k}_{x y}^{e H}\right]\right\}
$$

Here, lower limit $=\tilde{k}_{x y}^{r L}$ and higher limit $=\tilde{k}_{x y}^{r H}$

Further, average $\mathrm{RN}, \overline{\mathrm{N}\left(\tilde{k}_{x y}\right)}=\left[k_{x y}^{L}, k_{x y}^{H}\right]$ is calculated by Eq. (8-9).

$$
\begin{aligned}
& k_{x y}^{L}=\left(\sum_{r=1}^{e} k_{x y}^{r L}\right) / e \\
& k_{x y}^{H}=\left(\sum_{r=1}^{e} k_{x y}^{r H}\right) / e
\end{aligned}
$$

Here, lower limit of $\mathrm{RN}=k_{x y}^{L}$, higher limit of $\mathrm{RN}=k_{x y}^{H}$. 
As the transformation of expert ratings into $\mathrm{RN}$ is done, further a group rough DRM for the CSFs is formulated as Eq. (10).

$$
P_{k}=\left[\overline{\mathrm{N}\left(\tilde{k}_{x y}\right)}\right]_{s \times s}=\left[\begin{array}{cccc}
{[1,1]} & {\left[k_{12}^{L}, k_{12}^{H}\right]} & \cdots & {\left[k_{1 s}^{L}, k_{1 s}^{H}\right]} \\
{\left[k_{21}^{L}, r_{21}^{H}\right]} & {[1,1]} & \cdots & k_{2 s}^{r} \\
\vdots & \vdots & \ddots & \vdots \\
{\left[k_{s 1}^{L}, k_{s 1}^{H}\right]} & {\left[k_{s 2}^{L}, k_{s 2}^{H}\right]} & \cdots & {[1,1]}
\end{array}\right]
$$

\section{Step 3. Rough TRM formulation}

The constructed group rough DRM $P_{k}$ is normalized to achieve the matrix $P_{k}^{\prime}$ as Eq. (11). To normalize formulas, a linear scale transformation is used.

$$
P_{k}^{\prime}=\left[\overline{\mathrm{N}\left(\tilde{k}_{x y}\right)^{\prime}}\right]_{s \times s}=\left[\begin{array}{cccc}
\overline{\mathrm{N}\left(\tilde{k}_{11}\right)^{\prime}} & \overline{\mathrm{N}\left(\tilde{k}_{12}\right)^{\prime}} & \cdots & \overline{\mathrm{N}\left(\tilde{k}_{1 s}\right)^{\prime}} \\
\overline{\mathrm{N}\left(\tilde{k}_{21}\right)^{\prime}} & \frac{\mathrm{N}\left(\tilde{k}_{22}\right)^{\prime}}{\cdots} & \overline{\mathrm{N}\left(\tilde{k}_{2 s}\right)^{\prime}} \\
\frac{\vdots}{\mathrm{N}\left(\tilde{k}_{s 1}\right)^{\prime}} & \frac{\ddots}{\mathrm{N}\left(\tilde{k}_{s 2}\right)^{\prime}} & \cdots & \frac{\vdots}{\mathrm{N}\left(\tilde{k}_{s s}\right)^{\prime}}
\end{array}\right]
$$

Here,

$$
\begin{gathered}
\overline{\mathrm{N}\left(\tilde{k}_{x y}\right)^{\prime}}=\frac{\overline{\mathrm{N}\left(\tilde{k}_{x y}\right)}}{\beta}=\left[\frac{k_{x y}^{L}}{\beta}, \frac{k_{x y}^{H}}{\beta}\right] \\
\mathrm{Q}=\max _{1 \leq x \leq s}\left(\sum_{y=1}^{s} k_{x y}^{H}\right)
\end{gathered}
$$

Rough group TRM $\tau$ for the CSFs can be attained as follows.

$$
\begin{gathered}
\tau=\left[t_{x y}\right]_{s \times s} \\
t_{x y}=\left[t_{x y}^{L}, t_{x y}^{H}\right] \\
\tau^{\varnothing}=\left[t_{x y}^{\varnothing}\right]_{s \times s}=P_{k}^{\prime \varnothing}\left(I-P_{k}^{\prime \varnothing}\right)^{-1}, \varnothing=(L, H)
\end{gathered}
$$

where, lower limit of rough interval $t_{x y}=t_{x y}^{L}$, higher limit of rough interval $t_{x y}=t_{x y}^{H}$ and identity matrix $=I$.

Step 4. Rough sum of rows and rough sum of columns calculation

The rough sum of rows and columns are denoted as $V_{x}$ and $W_{y}$, respectively, for the group rough TRM,

$$
\left\{\begin{array}{c}
V_{x}=\left[v_{x}^{L}, v_{x}^{H}\right]=\left[\sum_{y=1}^{s} t_{x y}^{L}, \sum_{y=1}^{s} t_{x y}^{H}\right] \\
W_{y}=\left[w_{y}^{L}, w_{y}^{H}\right]=\left[\sum_{x=1}^{s} t_{x y}^{L}, \sum_{x=1}^{s} t_{x y}^{H}\right]
\end{array}\right.
$$

Step 5. Rough-relation and rough-prominence calculation

Total sum of $x^{\text {th }}$ row (showing causal influence) and $y^{\text {th }}$ column (showing effective influence) are demonstrated by $\tilde{M}_{x}$ and $\tilde{Z}_{x}$ respectively. Here, $\tilde{M}_{x}$ is called 'rough-prominence' and rough-prominence value specifies how important a particular CSF is. Greater value of $\tilde{M}_{x}$ indicates greater degree of relation of one factor with respect to other factors. $\tilde{Z}_{x}$ is called 'rough-relation' and it separates the factors into cause and effect groups. Positive value of 


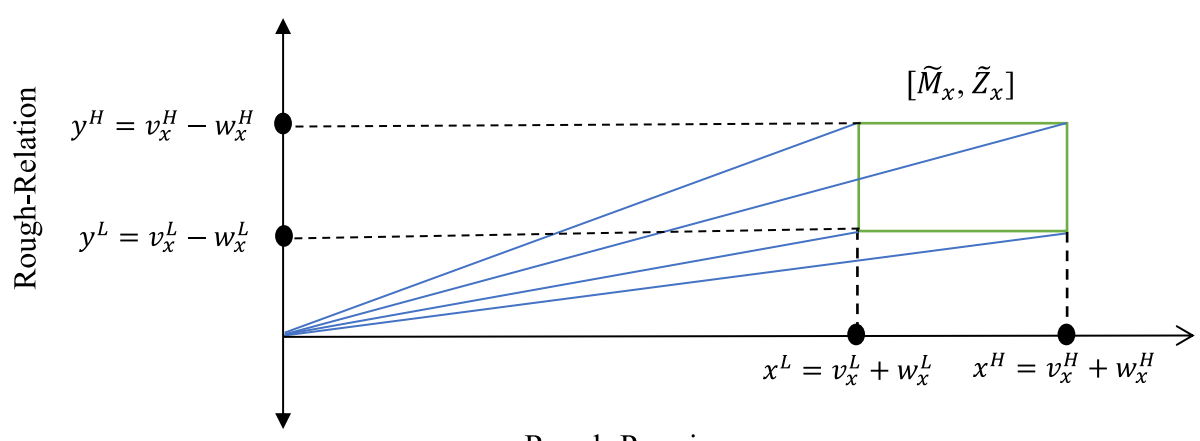

Rough-Prominence

Fig. 3 Four vector lengths for CSFs

$\tilde{Z}_{x}$ indicates that the factors fall into the cause group, while a negative value indicates that the factors fall into the effect group.

$$
\left\{\begin{array}{l}
\tilde{M}_{x}=V_{x}+W_{x}=\left[v_{x}^{L}+w_{x}^{L}, v_{x}^{H}+w_{x}^{H}\right] \\
\tilde{Z}_{x}=V_{x}-W_{x}=\left\lceil v_{x}^{L}-w_{x}^{L}, v_{x}^{H}-w_{x}^{H}\right\rceil
\end{array} \quad x=y=1,2, \ldots, s\right.
$$

\section{Step 6. Utilization of average vector-length $(A V L)$ to determine CSFs prioritization}

Rough-relation and rough-prominence values will help distinguish the most critical CSFs and achieve the importance weights of CSFs. AVL, $L_{x}$ and importance weight of $x$ th factors are obtained using Eq. (19) to prioritize CSFs. The greater the value of $\omega_{x}$ for a factor, the bigger the influence it has compared to other factors.

$$
\left\{\begin{array}{l}
L_{x}=\frac{\sqrt{\left(x^{L}\right)^{2}+\left(y^{L}\right)^{2}}+\sqrt{\left(x^{L}\right)^{2}+\left(y^{H}\right)^{2}}+\sqrt{\left(x^{H}\right)^{2}+\left(y^{L}\right)^{2}}+\sqrt{\left(x^{H}\right)^{2}+\left(y^{H}\right)^{2}}}{4} \\
\omega_{x}=L_{x} / \sum_{x=1}^{s} L_{x}
\end{array}\right.
$$

Figure 3 demonstrates how four vector-lengths are obtained where each of them is initiated from the origin and extended to each vertex of rough dataset $\left[\tilde{M}_{x}, \tilde{Z}_{x}\right]$.

\section{Application of the proposed method: an illustration}

To initiate the revised rough-DEMATEL method, three experts were approached to give weightage using a four-point scale to the identified CSFs. Due to the limited number of experienced people in this particular field of concurrent emergencies along with the restrictions imposed for COVID-19, only three experts from this field could be reached for rating the CSFs. Two of them were actively related to the concurrent emergency management team (floods amid COVID-19) of Bangladesh. The other is an academic who has research experience of more than 10 years in the field of EM. Further, to overcome this problem caused for the unavailability of adequate experts, a sensitivity analysis is done to confirm the robustness of the obtained results and the proposed method. 
Table 5 Rough sum of row and rough sum of column

\begin{tabular}{lllll}
\hline Factors & $V_{L}$ & $W_{L}$ & $V_{H}$ & $W_{H}$ \\
\hline CSF1 & 2.0056 & 2.0042 & 3.7264 & 3.7624 \\
CSF2 & 2.5916 & 2.0414 & 4.6626 & 3.8212 \\
CSF3 & 1.9946 & 2.2376 & 3.7912 & 4.0660 \\
CSF4 & 2.1537 & 2.1176 & 3.9263 & 3.8846 \\
CSF5 & 2.4326 & 2.3137 & 4.4004 & 4.2558 \\
CSF6 & 1.8140 & 2.3841 & 3.4090 & 4.3616 \\
CSF7 & 2.7851 & 2.4303 & 4.8863 & 4.3712 \\
CSF8 & 1.8917 & 2.1365 & 3.4159 & 4.0295 \\
CSF9 & 2.3637 & 1.8809 & 4.3386 & 3.6232 \\
CSF10 & 2.0529 & 2.0433 & 3.8394 & 3.8225 \\
CSF11 & 2.2036 & 2.1307 & 4.1051 & 3.9232 \\
CSF12 & 1.6949 & 2.2637 & 3.3671 & 3.9472 \\
\hline
\end{tabular}

\subsection{Results}

Step 1. A primary group DRM is created based on experts' ratings using Eqs. (1-2), shown in Table 12 ("Appendix A").

Step 2. Following Eqs. (3-10), group rough DRM is obtained, shown in Table 13 ("Appendix A"). The primary group DRM is constructed based on expert opinion, so in order to eliminate ambiguity this conversion into RNs is performed.

Step 3. The lower and higher estimation values obtained in step 2 are further normalized using Eqs. (11-16) and group rough TRM is formed. Tables 14 and 15 ("Appendix A") demonstrate normalized lower and higher approximation value, respectively.

Step 4. Table 5 is constructed using Eq. (17) which comprises the lower as well as upper estimations for rough sum of row and column.

Step 5. The data set obtained in Step 4 is further utilized to find rough-relation and roughprominence matrix using Eq. (18), presented in Table 6.

Step 6. Rough relation and rough prominence matrix are finally utilized to attain the AVL and importance weight following Eq. (19). The obtained values are shown in Table 7.

\subsection{Discussion of key findings}

Figures 4 and 5 demonstrate that the 12 CSFs are clustered into cause group and effect group. According to the values of rough relation, CSF2, CSF4, CSF5, CSF6, CSF7, CSF9, CSF10 and CSF11 are grouped into the cause category as they demonstrate positive values. All the cause group factors are critical to improve the CEM and minimize adverse effects of the concurrent emergencies. 'Incremental improvement of proactive measures (CSF7)' occupies the first position on the basis of AVL and weight value in the cause group with a score of $(0.3548,0.5151)$ indicating that it is of the highest significance for effective operation of CEM. The management must update the measures and policies formulated to handle concurrent emergencies constantly. Coincidence of two emergencies demands a unique set of measures to handle both simultaneously and these measures are dependent on the nature 
Table 6 Rough-relation and rough-prominence matrix

\begin{tabular}{|c|c|c|c|c|c|}
\hline \multirow[t]{2}{*}{ Factors } & \multicolumn{2}{|l|}{ Rough-relation } & \multicolumn{2}{|c|}{ Rough-prominence } & \multirow[t]{2}{*}{ Group } \\
\hline & $y^{L}=V_{L}-W_{H}$ & $y^{H}=V_{L}-W_{H}$ & $x^{L}=V_{L}+W_{H}$ & $x^{H}=V_{L}+W_{H}$ & \\
\hline CSF1 & -0.0014 & -0.0360 & 4.0098 & 7.4888 & Effect factor \\
\hline CSF2 & 0.5502 & 0.8414 & 4.6330 & 8.4837 & Cause factor \\
\hline CSF3 & -0.2430 & -0.2748 & 4.2322 & 7.8573 & Effect factor \\
\hline CSF4 & 0.0361 & 0.0417 & 4.2712 & 7.8109 & Cause factor \\
\hline CSF5 & 0.1189 & 0.1447 & 4.7463 & 8.6562 & Cause factor \\
\hline CSF6 & 0.5701 & 0.9525 & 4.1980 & 7.7706 & Cause factor \\
\hline CSF7 & 0.3548 & 0.5151 & 5.2155 & 9.2575 & Cause factor \\
\hline CSF8 & -0.2448 & -0.6136 & 4.0283 & 7.4454 & Effect factor \\
\hline CSF9 & 0.4827 & 0.7154 & 4.2446 & 7.9619 & Cause factor \\
\hline CSF10 & 0.0095 & 0.0169 & 4.0962 & 7.6619 & Cause factor \\
\hline CSF11 & 0.0729 & 0.1819 & 4.3343 & 8.0282 & Cause factor \\
\hline CSF12 & -0.5688 & -0.5802 & 3.9586 & 7.3143 & Effect factor \\
\hline
\end{tabular}

Table 7 Prioritization of CSFs by AVL

\begin{tabular}{lllr}
\hline Factors & AVL & Weight & Rank \\
\hline CSF1 & 5.7493 & 0.01941 & 11 \\
CSF2 & 6.6003 & 0.02228 & 3 \\
CSF3 & 6.0509 & 0.02043 & 6 \\
CSF4 & 6.0412 & 0.02039 & 7 \\
CSF5 & 6.7027 & 0.02263 & 2 \\
CSF6 & 6.0404 & 0.02039 & 8 \\
CSF7 & 7.2511 & 0.02448 & 1 \\
CSF8 & 5.7577 & 0.01944 & 10 \\
CSF9 & 6.1367 & 0.02072 & 5 \\
CSF10 & 5.8791 & 0.01985 & 9 \\
CSF11 & 6.1830 & 0.02087 & 4 \\
CSF12 & 5.6684 & 0.01913 & 12 \\
\hline
\end{tabular}

of individual emergencies as well as the additional risks that are created by the coincidence of emergencies. Therefore, the proactive measures taken by the CEM must be under constant update and improvement as per the nature of the concurrent emergencies.

The factor having the second-highest rank on the basis of AVL and weight value in cause group is 'Resilient supply chain and logistics network (CSF5)' with a score of (0.1189, 0.1447). Concurrent emergencies disrupt the supply chain and logistics network drastically. As a result, the aid supply discontinues and measures that rely on these disrupted supply chains and the logistics network get severely hindered. To avoid such instances, supply chain and logistics networks need to become more flexible to recover quickly from difficult conditions (Dubey et al., 2019a, b). 


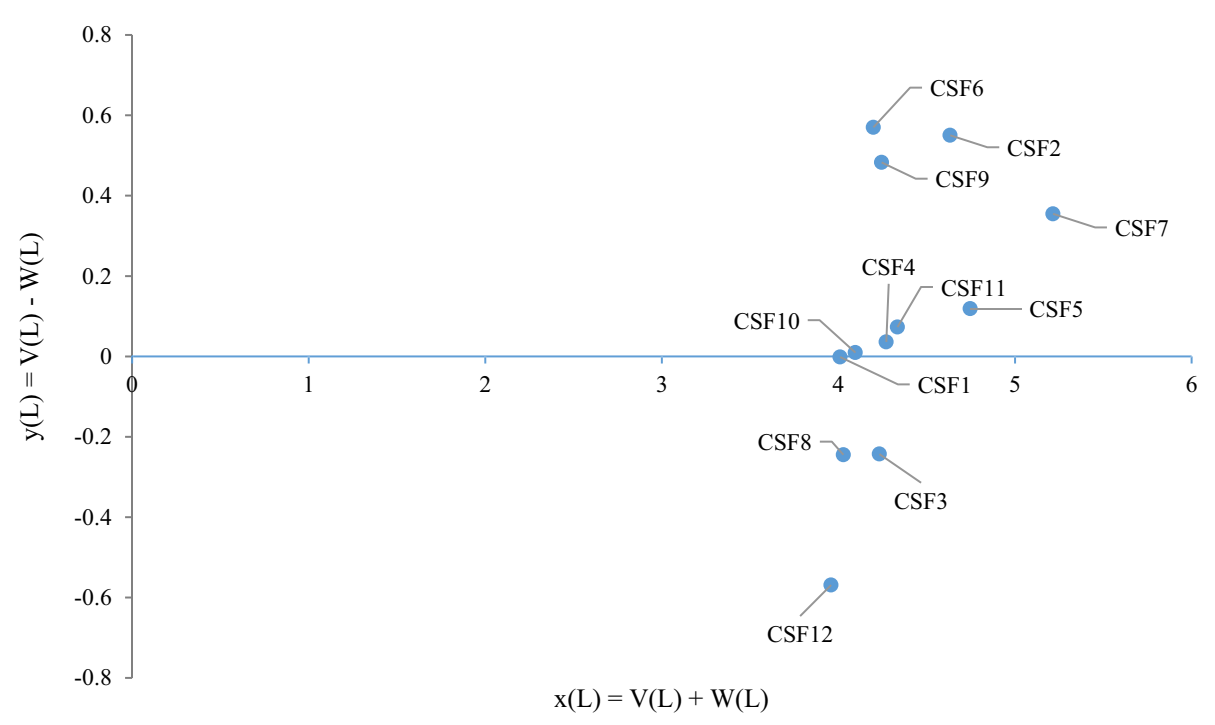

Fig. 4 Causal relationship diagram (lower estimation)

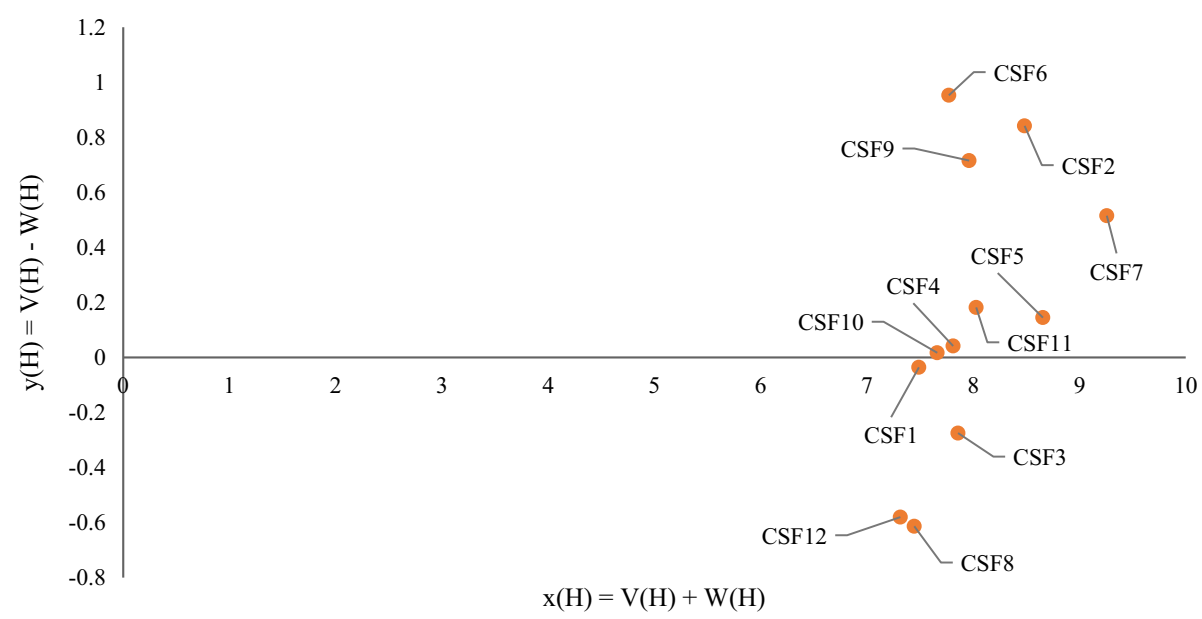

Fig. 5 Causal relationship diagram (higher estimation)

'Government leadership and military cooperation (CSF2)' ranks third in cause group based on AVL and weight value with a score of $(0.5502,0.8414)$. Several researches have highlighted the importance of power lead government can take to coordinate all the parts of EM and enhance the execution efficiency of emergency response plans (Rivera et al., 2020). Government leadership in developing an emergency response management framework together with the cooperation of armed forces can reduce the vulnerability of CEM. 'Adequate and available financial resources (CSF11)' takes the fourth position in cause group. Management of concurrent emergencies requires a huge amount of financial resources and 
for smooth operation of CEM funds must be readily available in sufficient amount. Government is responsible for ensuring the availability of financial resources. The raking within the cause group is as follows: CSF7 > CSF5 $>$ CSF2 $>$ CSF11 > CSF9 > CSF4 > CSF6 > CSF10.

According to the value of rough relation, CSF1, CSF3, CSF8 and CSF12 are grouped into the effect category as they demonstrate negative values. All the factors of effect group are considered to be less important compared to the factors of cause groups. 'Prevent corruption in aid distribution (CSF3)' occupies the first position in the effect group with a score of ($0.2430,-0.2748$ ). Cause factors such as 'Government leadership and military cooperation (CSF2)' and 'Availability of effective need and resource assessment tools (CSF10)' influence the prevention of aid distribution corruption. Without ensuring the integrity of aid distribution all the other efforts to improve CEM, such as resilient supply chains, adequate financial resources can go in vain. The ranking within the effect group is as follows: CSF3 > CSF8 > CSF1 > CSF12.

The overall ranking obtained on the basis of the AVL value is as follows: CSF7 $>$ CSF5 $>$ CSF2 > CSF1 $1>$ CSF9 $>$ CSF3 $>$ CSF4 $>$ CSF6 $>$ CSF10 $>$ CSF8 $>$ CSF1 > CSF12. Here, the top five CSFs are: Incremental improvement of proactive measures, Resilient supply chain and logistics network, Government leadership and military cooperation, Adequate and available financial resources and, clearly stated instructions, quick feedback and early warning.

\subsection{Sensitivity analysis}

In this section, an archetypal sensitivity analysis is done to confirm the robustness of the obtained results by assigning the highest weightage to one of the three experts in three different scenarios while keeping equal weightage for the others (Moktadir et al., 2018; Rajesh \& Ravi, 2015). Table 8 demonstrates different weights assigned to the experts for three different scenarios.

The analysis results are demonstrated in Table 9. This table depicts the rankings of factors according to AVL, where CSF7 (incremental improvement of proactive measures) occupies the top position in all the scenarios similar to the results obtained previously. There are some negligible order discrepancies, mainly in the rankings of intermediate factors which is acceptable. Therefore, the robustness of obtained results is confirmed by the sensitivity analysis. Table 10 shows the cause and effect factors obtained from these three scenarios. CSF3, CSF8 and CSF12 are characterized as the effect factors for all three scenarios consistent with the previous results. However, in scenario 2 and scenario 3, 'Prioritization of the preparedness phase actions (CSF6)' is found to be in the effect group. Furthermore, in scenario 1, 'Empowerment of emergency response management team (CSF1)' is characterized as cause factor rather than effect factor as found before. Besides these minor discrepancies, the sensitivity

Table 8 Weights assigned to experts for sensitivity analysis

\begin{tabular}{llll}
\hline Scenario & \multicolumn{2}{l}{ Expert } & \\
\cline { 2 - 4 } & 1 & 2 & 3 \\
\hline 1 & 0.50 & 0.25 & 0.25 \\
2 & 0.25 & 0.50 & 0.25 \\
3 & 0.25 & 0.25 & 0.50 \\
\hline
\end{tabular}


Table 9 Ranking of CSFs from sensitivity analysis

\begin{tabular}{|c|c|c|c|c|c|c|}
\hline \multirow[t]{2}{*}{ Factors } & \multicolumn{2}{|c|}{ Scenario 1} & \multicolumn{2}{|c|}{ Scenario 2} & \multicolumn{2}{|c|}{ Scenario 3} \\
\hline & $\mathrm{AVL}$ & Rank & AVL & Rank & AVL & Rank \\
\hline CSF1 & 4.6664 & 10 & 4.5566 & 10 & 3.9296 & 11 \\
\hline CSF2 & 5.5133 & 3 & 5.1290 & 4 & 4.5259 & 3 \\
\hline CSF3 & 4.8696 & 6 & 4.9871 & 6 & 4.1574 & 6 \\
\hline CSF4 & 4.7632 & 8 & 4.7019 & 8 & 4.0044 & 8 \\
\hline CSF5 & 5.5499 & 2 & 5.2840 & 2 & 4.5289 & 2 \\
\hline CSF6 & 4.8199 & 7 & 4.7625 & 7 & 4.0472 & 7 \\
\hline CSF7 & 5.8884 & 1 & 5.5101 & 1 & 4.9831 & 1 \\
\hline CSF8 & 4.5365 & 12 & 4.5276 & 11 & 3.9316 & 10 \\
\hline CSF9 & 4.8766 & 5 & 5.1026 & 5 & 4.1729 & 5 \\
\hline CSF10 & 4.6966 & 9 & 4.6392 & 9 & 3.9637 & 9 \\
\hline CSF11 & 5.0079 & 4 & 5.1398 & 3 & 4.3113 & 4 \\
\hline CSF12 & 4.5771 & 11 & 4.5134 & 12 & 3.7655 & 12 \\
\hline
\end{tabular}

Table 10 Cause and effect factors from sensitivity analysis

\begin{tabular}{lll}
\hline Scenario & CSFs & \\
\hline Scenario 1 & Cause factors & CSF1, CSF2, CSF4, CSF5, CSF7, CSF9, CSF10, CSF11 \\
& Effects factors & CSF3, CSF6, CSF8, CSF12 \\
Scenario 2 & Cause factors & CSF2, CSF4, CSF5, CSF7, CSF9, CSF10, CSF11 \\
& Effects factors & CSF1, CSF3, CSF6, CSF8, CSF12 \\
Scenario 3 & Cause factors & CSF2, CSF4, CSF5, CSF6, CSF7, CSF9, CSF10, CSF11 \\
& Effects factors & CSF1, CSF3, CSF8, CSF12 \\
\hline
\end{tabular}

analysis yields result very similar to the result obtained in Sect. 4, proving the robustness of the obtained results from this study. The sensitivity results are shown in Figs. 6 and 7, which indicate that the obtained AVL and the rank of CSFs, respectively. The results obtained also were discussed with a validation group consisting six of our survey respondents and they supported the findings and advocated that the identified CSFs can be beneficial for effective in handling future concurrent emergencies. The validation group particularly resonated with the specified cause effect relationships of CSFs and emphasized that it can play a major role in the process of decision making. Ultimately, the obtained results got certification of validation group.

\section{Validation of proposed method}

In this section, a comparative analysis is done to verify the robustness of the proposed method. Froe illustrating the efficiency and feasibility of the proposed revised rough DEMATEL 


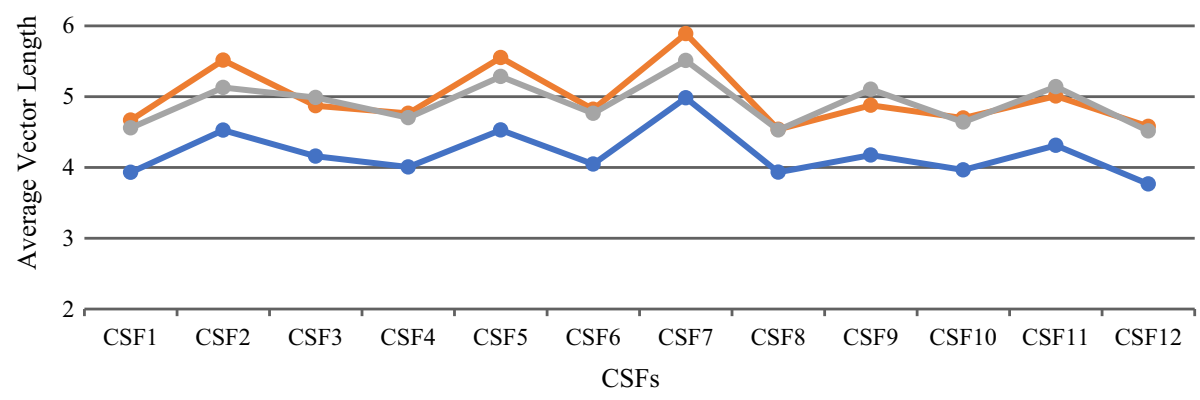

Fig. 6 AVL obtained from sensitivity analysis

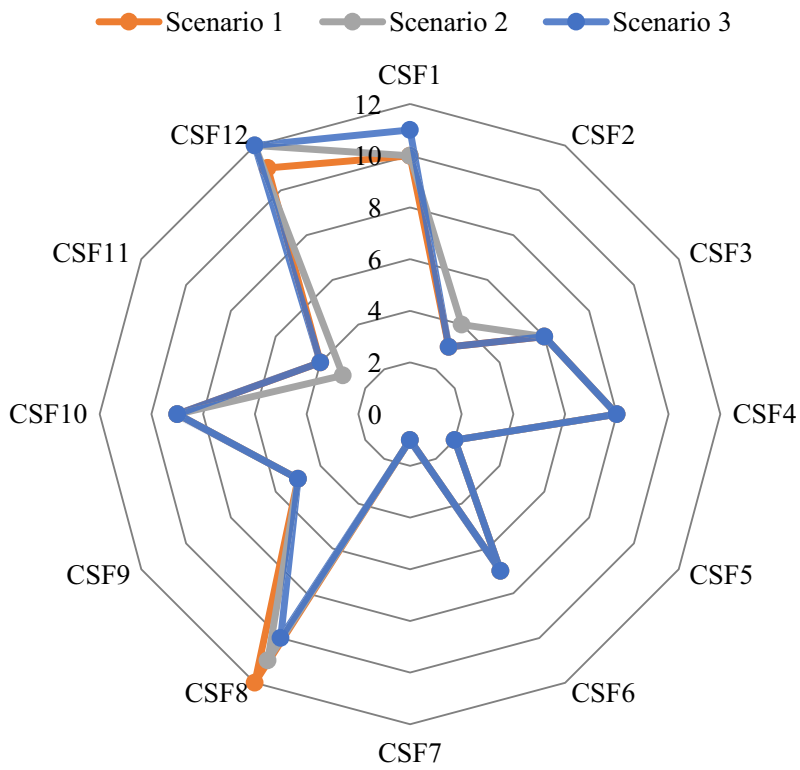

Fig. 7 Ranking of CSFs according to AVL obtained from sensitivity analysis

approach, a comparative analysis is conducted by applying fuzzy DEMATEL (Lin et al., 2018) and grey DEMATEL (Bhatia \& Srivastava, 2018) method for the same case study.

In comparison with fuzzy DEMATEL, revised rough DEMATEL method can better reflect the objectivity of expert evaluation results while combining the judgements of multiple experts (Zhai et al., 2008). Revised rough DEMATEL performs better than grey DEMATEL method while working with limited information. Furthermore, contrasting with rough DEMATEL method, revised rough DEMATEL includes a feasible operator AVL that excludes the need for additional de-roughness (Liu \& Ming, 2019). For fuzzy DEMATEL the CSFs are ranked as follows: CSF7 $>$ CSF5 $>$ CSF2 $>$ CSF1 $1>$ CSF4 $>$ CSF3 $>$ CSF9 $>$ CSF6 $>$ CSF10 $>$ CSF8 $>$ CSF1 $>$ CSF12 and for grey DEMATEL the CSFs are ranked as follows: CSF7 > 
$\mathrm{CSF} 5>\mathrm{CSF} 2>\mathrm{CSF} 11>\mathrm{CSF} 9>\mathrm{CSF} 4>\mathrm{CSF} 3>\mathrm{CSF} 6>\mathrm{CSF} 10>\mathrm{CSF} 8>\mathrm{CSF} 1>\mathrm{CSF} 12$. The computed comparative results are shown in Fig. 8. All these three methods identify CSF7 (incremental improvement of proactive measures) as the most critical success factor. The top four critical factors are similar according to these three methods. From Figs. 9 and 10, it can be seen that the factors CSF1, CSF3, CSF8 and CSF12 fall under the effect group and factors CSF2, CSF4, CSF5, CSF7, CSF9, CSF10 and CSF11 fall under the cause group for all three methods. Grey DEMATEL identified CSF6 as a cause factor same as revised rough

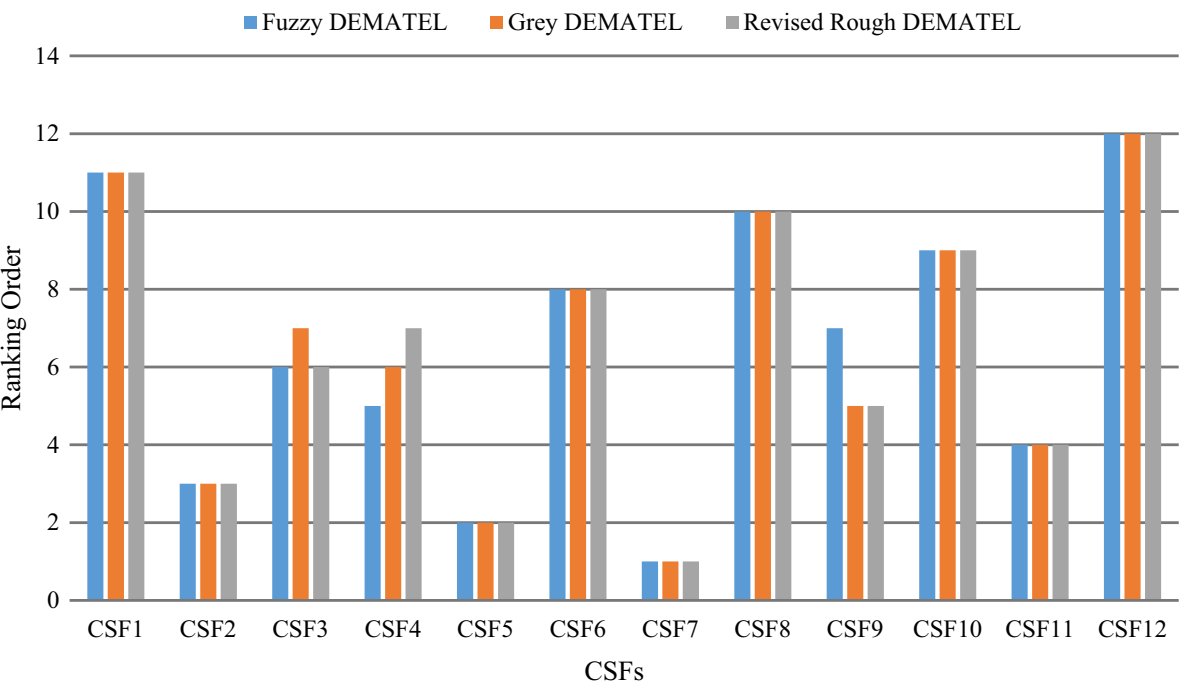

Fig. 8 Ranking order comparison

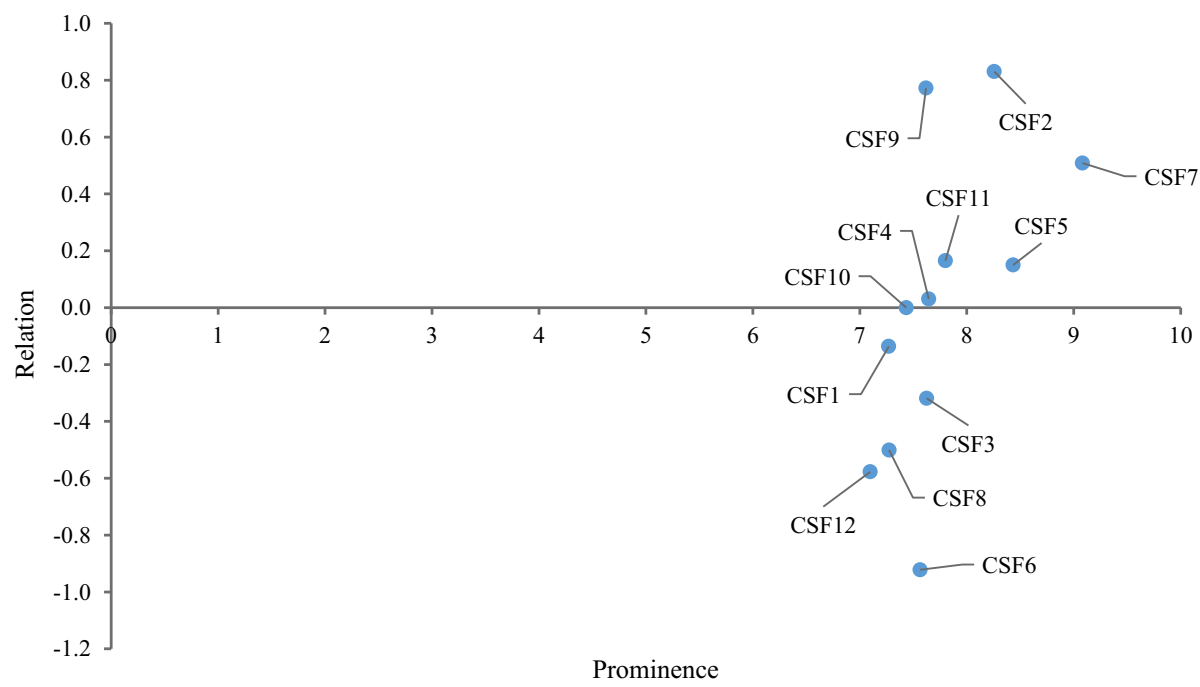

Fig. 9 Prominence-relation diagram for Fuzzy DEMATEL 


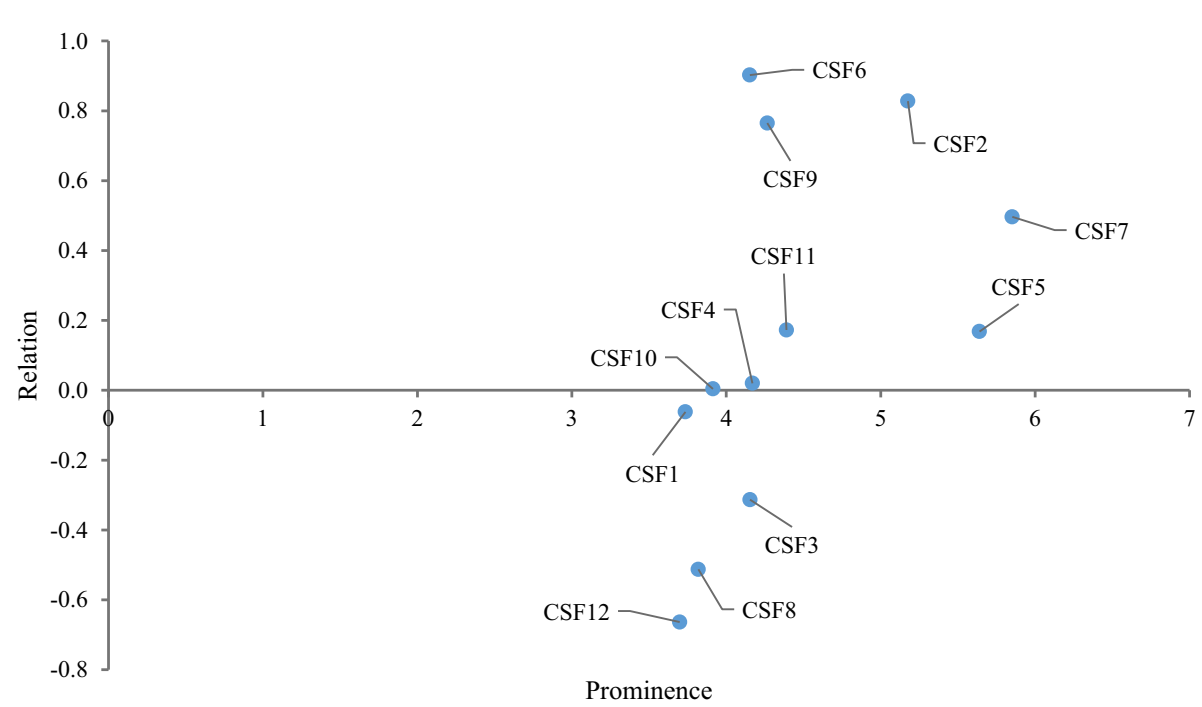

Fig. 10 Prominence-relation diagram for Grey DEMATEL

DEMATEL, however fuzzy DEMATEL classified it as an effect factor. Almost identical ranking order except minor variations verifies the legitimacy of the proposed method. From the discussion above, it can be seen that all three methods have classified the CSFs similarly into cause and effect factors, which verifies the ability of the proposed method to identify CSFs in CEM system with additional advantages such as requiring less information, high judgement flexibility, elimination of fuzzy membership and non-membership calculation, elimination of additional de-roughness calculation elimination.

\section{Research implications}

\subsection{Implication to theory}

This research has some significant theoretical contributions. Firstly, this study has attempted for a better understanding of managing concurrent emergencies, which seem to be necessary at this time considering what the world has faced recently. The recent disasters among the COVID-19 outbreak have emphasized the importance of CEM and the need to introduce new approaches to handle unprecedented situations (Ebrahim et al., 2020; Phillips et al., 2020). Previously, emergencies were addressed individually; for example Rathnayake et al. (2020) explored the enablers of coastal disaster resilience during the 2004 Tsunami of Nepal. Prager et al. (2016) addressed the total economic consequences of an influenza outbreak in the United States of America. Meanwhile, it has become necessary to examine the actions in details taken by local management authorities while being encountered with concurrent emergencies (Ishiwatari et al., 2020). In this context, the present research contributes comprehensively for a better understanding of a less explored area of CEM. Secondly, the research undertakes an integration of systematic literature review, consultation from emergency management experts as well as academicians, and Pareto analysis to identify and finalize the CSFs of CEM considering the recent phenomenon of floods amid the COVID-19 outbreak 
in Bangladesh. The integrated model is different from similar previous studies. For example, Siriporananon and Visuthismajarn, (2018) identified the key success factors of disaster management in Hat Yai city, Thailand; however, their work concentrated solely on individual disasters. Thirdly, the research introduced a new approach, revised rough DEMATEL, to prioritize the critical factors of CEM, to identify the indispensable links among the CSFs, and to comprehend the relationships among CSFs to make a more informed decision. Ahmed et al. (2021) as well as Liu and Ming (2019) have advocated that the inclusion of rough aggregation approach allows researchers to handle interpersonal ambiguity by combining numerous judgements into a flexible rough intervals and eliminate the need for additional de-roughness by incorporating AVL providing a maximum level of accuracy. Finally, this study helps researchers to comprehend the ranking and causal links of CSFs of CEM, which in turn enables them to consider these CSFs while developing a parsimonious model of CEM in the context of any other developing nation. The findings of this research can trigger the interest of academics for further exploration of concurrent emergencies.

\subsection{Implication to practice}

The findings of the study provide initial guidance to the managers and decision-makers on the effective management of CEM. The study suggests a framework utilizing the revised rough-DEMATEL approach for prioritizing and analyzing CSFs of CEM. Managers and decision-makers can utilize this framework as a benchmark for enhancing the efficiency and effectiveness of CEM. This framework will help managers analytically organize their decision by computing the relative importance and influence of different CSFs. Furthermore, by using the proposed framework realistic judgements of group DMs under uncertain situations can easily be captured. The obtained ranking of the identified CSFs can be used as a checklist and can assist managers and decision-makers to handle concurrent emergencies systematically. The CSFs having a higher rank should be given more importance than others for ensuring effective CEM. The results reveal that incremental improvement of proactive measures, resilient supply chain and logistics network, government leadership and military cooperation are the top three CSFs. So, Managers must update the proactive measures regularly according to the unique demands of a concurrent emergency to effectively handle the situation (Modgil et al., 2020). To avoid supply chain disruptions caused by concurrent emergencies, managers should adopt more flexible and resilient supply chain networks (Dubey et al., 2020a, 2020b; Ivanov, 2020; Queiroz et al., 2020). For ensuring effective collaboration between government and armed forces in complex environments, managers need to realize the roles, capabilities, and information-sharing needs (Dubey et al., 2021; Dubey et al., 2020a, 2020b). Further, the cause and effect analysis among the CSFs identifies the cause and effect group where the cause group can easily influence the effect group. From a managerial perspective, it is crucial to know which CSFs are influential and which are influenced to decide the amount of attention given to each factor. This study will help managers to understand which CSF is more important and need greater attention. A greater emphasis on cause group CSFs can help to ensure effective CEM. Finally, policymakers will find this study useful to make proper decisions to improve CEM. The findings of this research will guide them while developing measures and policies, improving institutionalized strategies, confirming health and safety initiatives in CEM. The policymakers are recommended to consider the top five CSFs initially to ensure implementation of sustainability in CEM. 


\section{Conclusion, limitations and recommendations}

\subsection{Conclusion}

As the occurrence frequency of concurrent emergencies is likely to increase in future due to increased pollution and climate change, ensuring effective CEM has become essential. The whole CEM can be greatly facilitated by improving the CSFs. The research suggests the revised rough DEMATEL method to prioritize and analyze interrelationships between the CSFs of CEM. The proposed methodology was applied to a practical CEM case as an illustrative example to demonstrate its applicability. 'Incremental improvement of proactive measures' is identified to be the most crucial factor that influences CEM. Comparative and sensitivity analysis validate the use of the proposed research framework and proves the robustness of this method and obtained results.

This study contributes to both the literature and practice of CEM. The study initiates a new promising topic by identifying the CSFs of CEM which could create interest in researchers and practitioners for this topic to explore more from a primary level. Also, it provides practical managerial implications which are useful for CEM. It is more effective for managers to deal with a few predominant CSFs having greater impacts over the CEM. The findings of this study can assist managers in directing their efforts and resources to the most CSFs of CEM and reduce the havoc that these concurrent emergencies can create. CSFs of CEM are interconnected, as demonstrated in the projected digraphs, and this notion can assist managers to devote attention to the right factors that might yield more improvement in the management practices.

\subsection{Limitations and recommendations}

Though the proposed approach is capable of determining the CSFs of CEM, it has some limitations. The data have been gathered in context to a developing nation in the Asian continent. So, the obtained results may not be relevant for developed nations of other continents. However, this presents scope for further research. Data can be collected in the context of other continents and then findings can be compared with the present study. An inclusion of qualitative investigation can be considered for data collection. Also, only three experts from this field could be reached for rating the CSFs. Since the results are greatly dependent on expert judgement, it is a must that the expert has in-depth knowledge about the concerned topic which is challenging to ensure. Further, more experts can be added to overcome this limitation. Moreover, methods like D-DEMATEL, evidential DEMATEL, intuitionistic fuzzy DEMATEL, Bayesian best worst can be applied in further researches to compare the results and get more valuable insights.

\section{Appendix A}

See Tables 11, 12, 13, 14 and 15. 
Table 11 Pareto analysis of CSFs for CEM

\begin{tabular}{|c|c|c|}
\hline CSFs & Score & Cumulative percentage (\%) \\
\hline Availability of need and resource assessment tools & 218 & 11 \\
\hline Individual and community awareness & 213 & 23 \\
\hline $\begin{array}{l}\text { Empowerment of emergency response management } \\
\text { team }\end{array}$ & 202 & 33 \\
\hline Government leadership and military cooperation & 189 & 43 \\
\hline Prevent corruption in aid distribution & 183 & 53 \\
\hline $\begin{array}{l}\text { Improvement of proactive measures to handle } \\
\text { concurrent emergencies }\end{array}$ & 176 & 62 \\
\hline Psychological support & 168 & 71 \\
\hline $\begin{array}{l}\text { Clearly stated instructions and early caution about } \\
\text { potential dangers }\end{array}$ & 164 & 80 \\
\hline $\begin{array}{l}\text { Awareness of responsibilities and rational } \\
\text { organizational structure }\end{array}$ & 102 & 85 \\
\hline Minimum response time to initiate the emergency plan & 78 & 89 \\
\hline $\begin{array}{l}\text { Evaluation of the efficiency and effectiveness of } \\
\text { management system }\end{array}$ & 52 & 92 \\
\hline $\begin{array}{l}\text { Appropriate emergency response strategy and } \\
\text { regulations }\end{array}$ & 47 & 94 \\
\hline Reconstruction and staff comforting & 44 & 96 \\
\hline Periodic arrangement of disaster exercise simulation & 35 & 98 \\
\hline $\begin{array}{l}\text { Explicit procedure for reporting and submitting } \\
\text { information }\end{array}$ & 32 & 100 \\
\hline
\end{tabular}




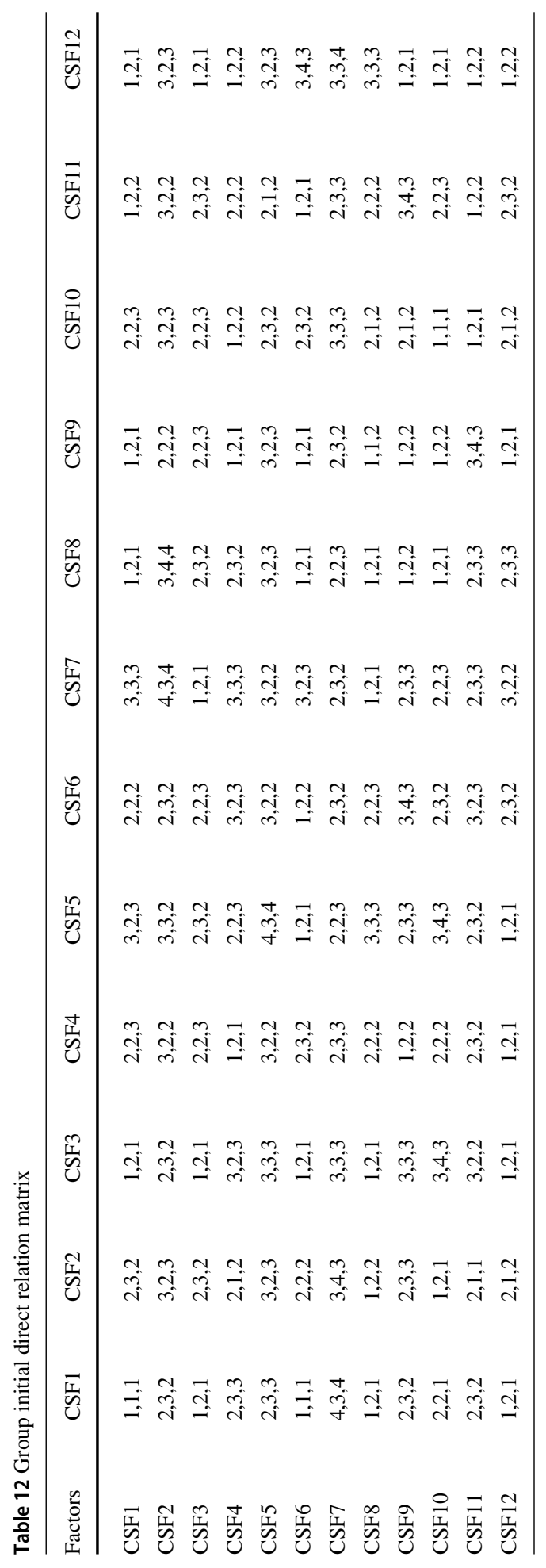




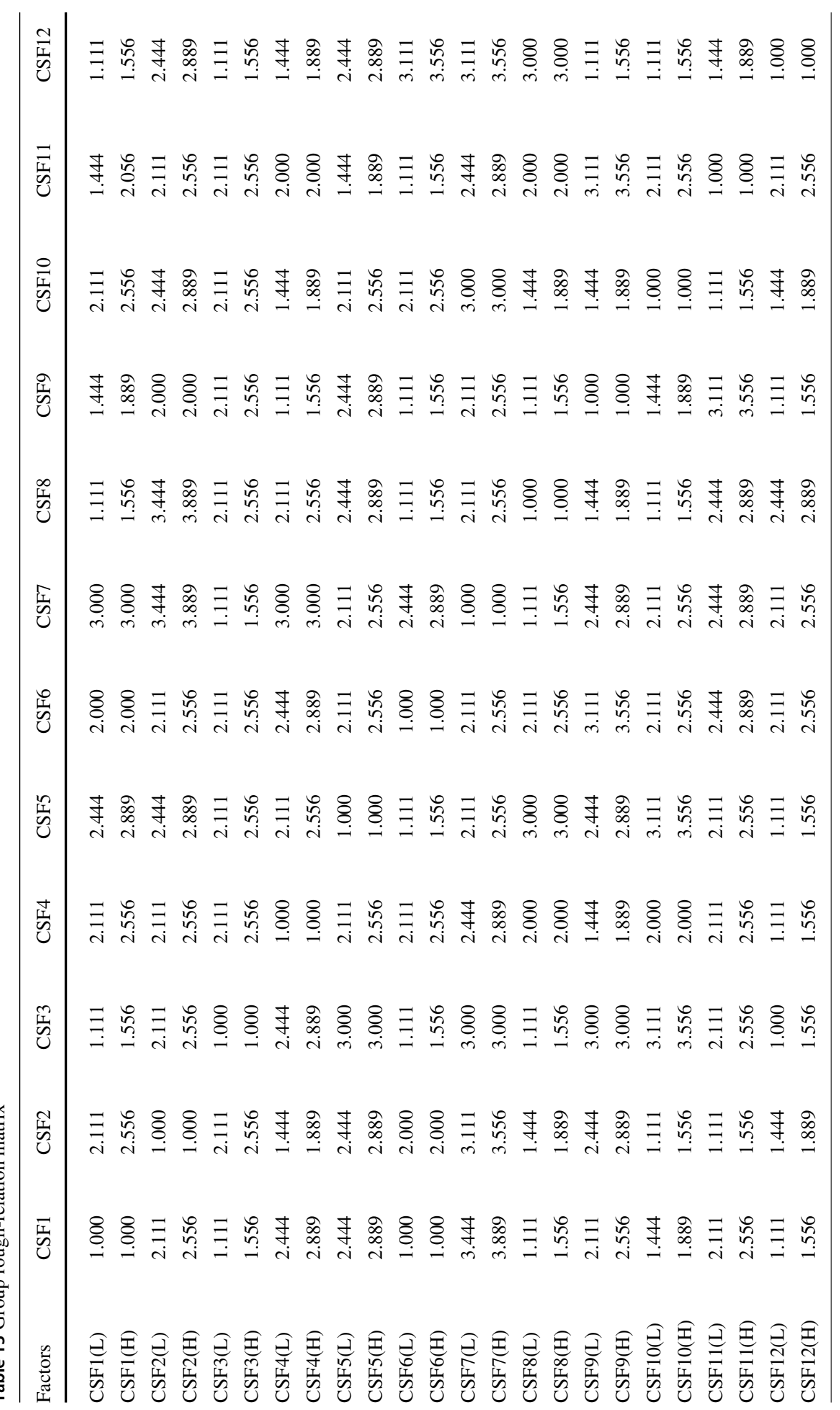




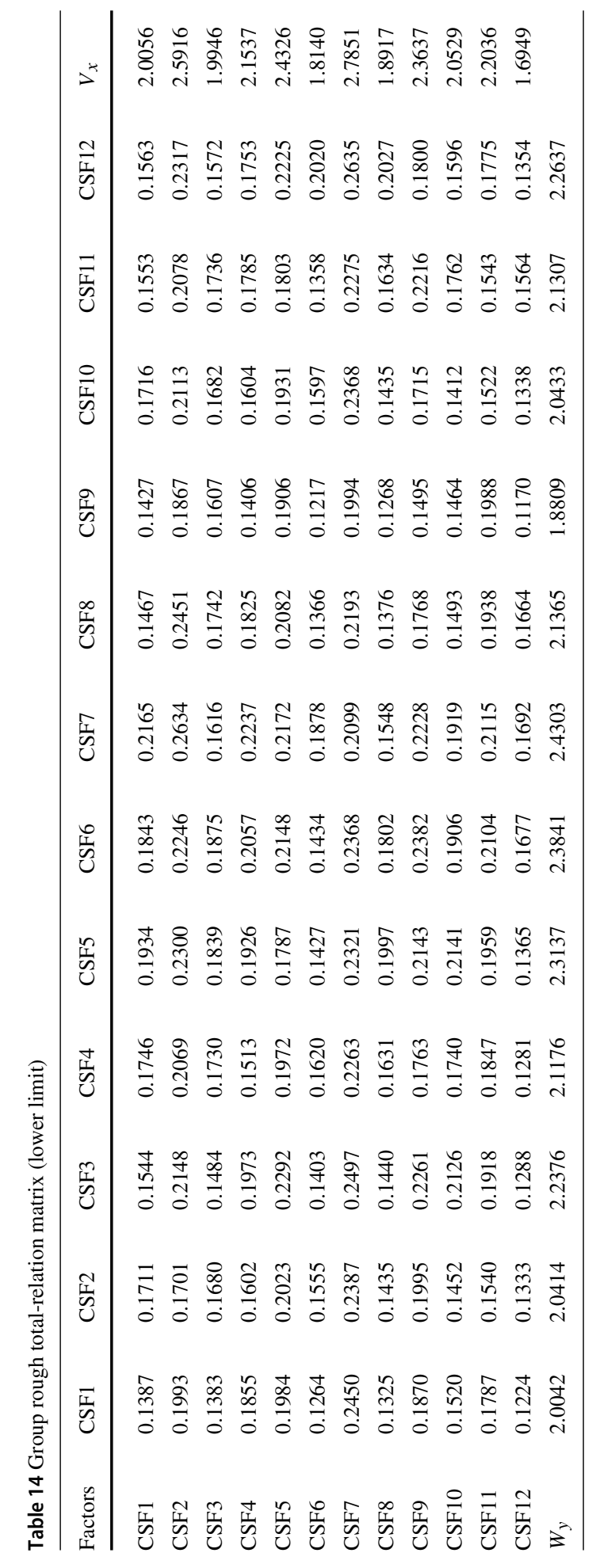




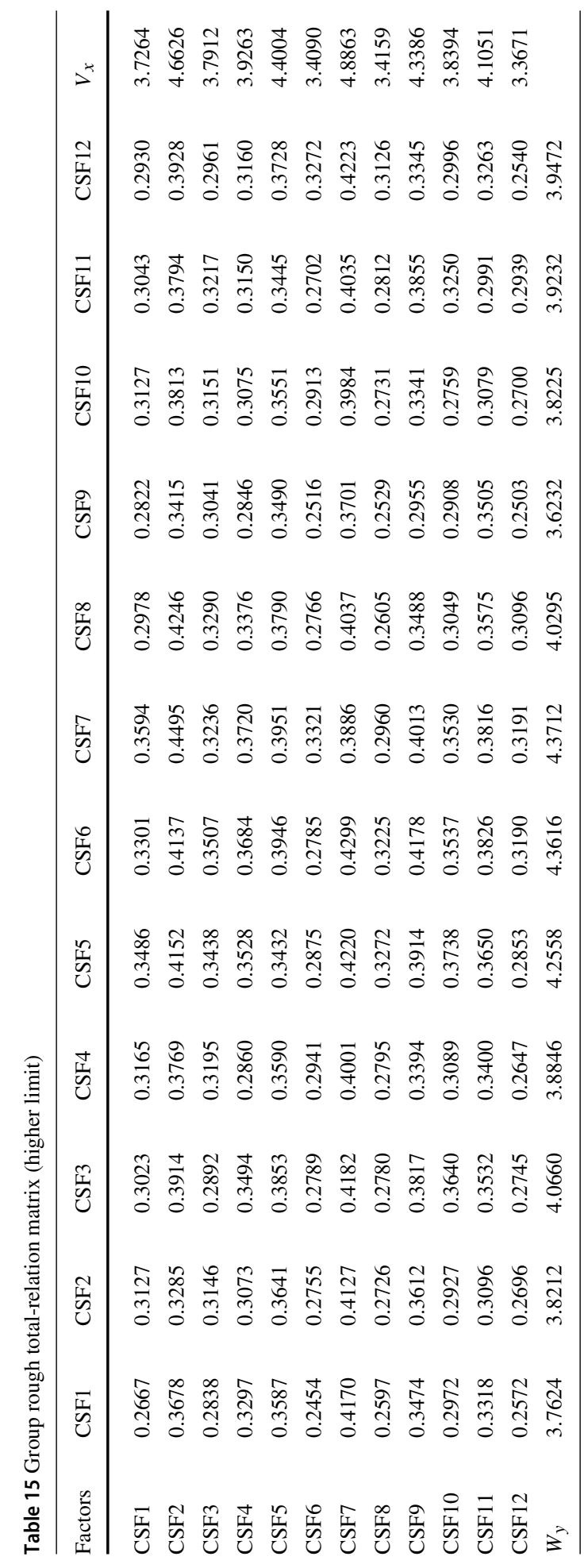




\section{Appendix B}

Questionnaire

1. Kindly answer the questions mentioned below:
(a) Name:
(b) Role/Job Position:
(c) Years of experience:

2. Identification of critical success factors (CSFs) of concurrent emergency management (CEM): Please specify which factors are relevant to CEM and modify the mentioned factors if needed. Further, give scores to your selected CSFs on a scale of 1-5 (5: very strongly significant and 1: very weakly significant). If you think other relevant and necessary factors are not mentioned in the table, please suggest.

\begin{tabular}{|c|c|c|c|c|c|c|c|c|}
\hline \multirow[t]{2}{*}{ No. } & \multirow[t]{2}{*}{ Factors } & \multirow[t]{2}{*}{ Yes/no } & \multicolumn{5}{|c|}{$\begin{array}{l}\text { 5: very strongly } \\
\text { significant and } \\
\text { 1: very weakly } \\
\text { significant }\end{array}$} & \multirow[t]{2}{*}{ Suggest modification } \\
\hline & & & 1 & 2 & 3 & 4 & 5 & \\
\hline 1 & $\begin{array}{l}\text { Periodic arrangement } \\
\text { of disaster exercise } \\
\text { simulation }\end{array}$ & & & & & & & \\
\hline 2 & $\begin{array}{l}\text { Empowerment of } \\
\text { emergency response } \\
\text { management team }\end{array}$ & & & & & & & \\
\hline 3 & $\begin{array}{l}\text { Reconstruction and } \\
\text { staff comforting }\end{array}$ & & & & & & & \\
\hline 4 & $\begin{array}{l}\text { Government } \\
\text { leadership and } \\
\text { military cooperation }\end{array}$ & & & & & & & \\
\hline 5 & $\begin{array}{l}\text { Prevent corruption in } \\
\text { aid distribution }\end{array}$ & & & & & & & \\
\hline 6 & $\begin{array}{l}\text { Improvement of } \\
\text { proactive measures } \\
\text { to handle concurrent } \\
\text { emergencies }\end{array}$ & & & & & & & \\
\hline 7 & $\begin{array}{l}\text { Evaluation of the } \\
\text { efficiency and } \\
\text { effectiveness of } \\
\text { management system }\end{array}$ & & & & & & & \\
\hline 8 & Psychological support & & & & & & & \\
\hline 9 & $\begin{array}{l}\text { Explicit procedure for } \\
\text { reporting and } \\
\text { submitting } \\
\text { information }\end{array}$ & & & & & & & \\
\hline 10 & $\begin{array}{l}\text { Minimum response } \\
\text { time to initiate the } \\
\text { emergency plan }\end{array}$ & & & & & & & \\
\hline
\end{tabular}




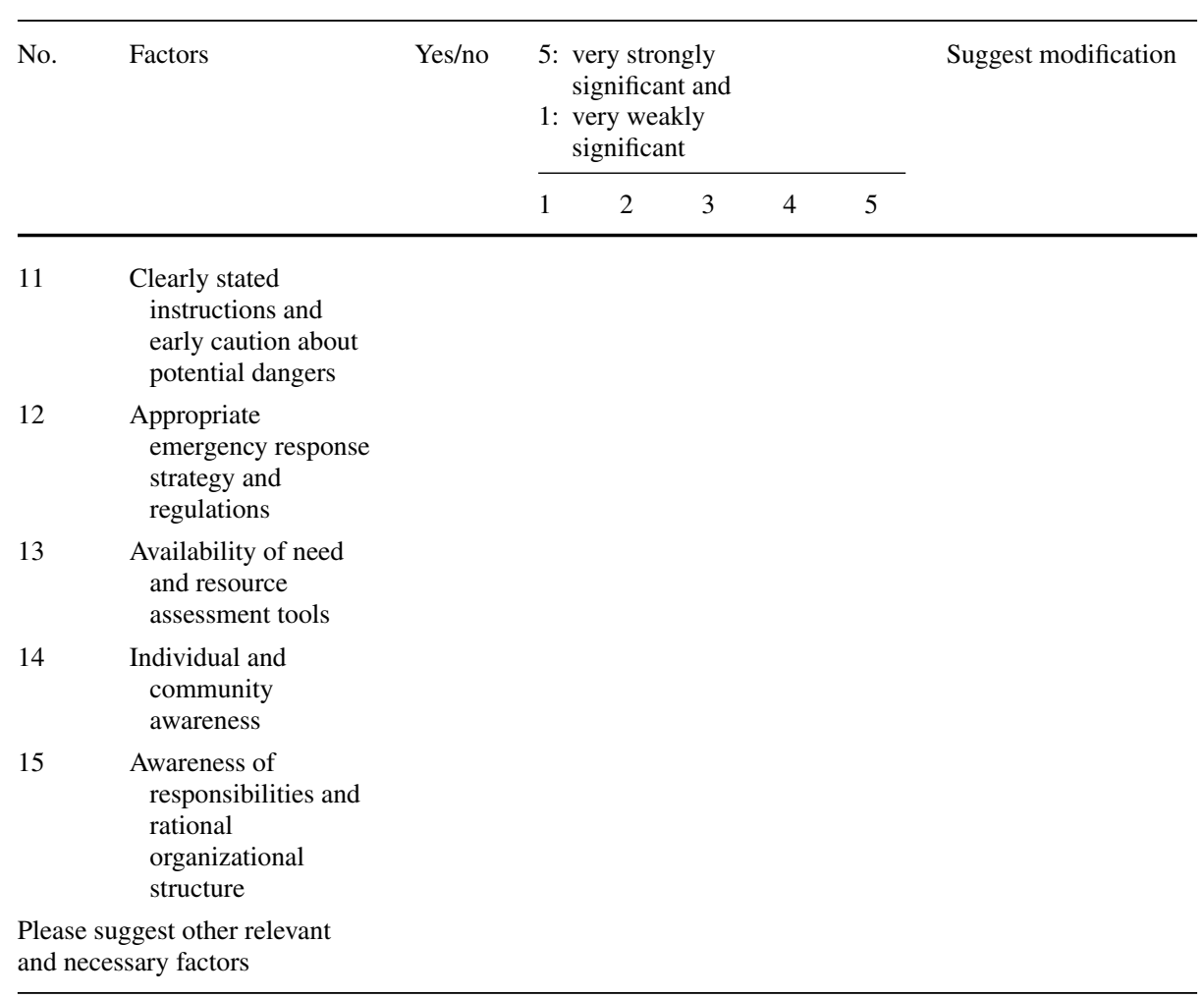

\section{References}

Aburas, W., \& Alshammari, T. M. (2020). Pharmacists' roles in emergency and disasters: COVID-19 as an example. Saudi Pharmaceutical Journal, 28(12), 1797-1816. https://doi.org/10.1016/j.jsps.2020.11.006

Adhikari, B., Ozaki, A., Marahatta, S. B., Rijal, K. R., \& Mishra, S. R. (2020). Earthquake rebuilding and response to COVID-19 in Nepal, a country nestled in multiple crises. Journal of Global Health, 10(2), 1-4. https://doi.org/10.7189/jogh.10.020367

Ahmed, S., Muhtasim, H., Yeasir, T., Farabi, I., Sarker, M., \& Mithun, S. (2021). Evaluation of flexible strategies to manage the COVID-19 pandemic in the education sector. Global Journal of Flexible Systems Management. https://doi.org/10.1007/s40171-021-00267-9

Aschemann-Witzel, J., de Hooge, I. E., Rohm, H., Normann, A., Bossle, M. B., Grønhøj, A., \& Oostindjer, M. (2017). Key characteristics and success factors of supply chain initiatives tackling consumer-related food waste-A multiple case study. Journal of Cleaner Production, 155(July), 33-45. https://doi.org/10. 1016/j.jclepro.2016.11.173

Bai, C., \& Sarkis, J. (2013). A grey-based DEMATEL model for evaluating business process management critical success factors. International Journal of Production Economics, 146(1), 281-292. https://doi. org/10.1016/j.ijpe.2013.07.011

Banik, A., Taqi, H. M. M., Ali, S. M., Ahmed, S., Garshasbi, M., \& Kabir, G. (2020). Critical success factors for implementing green supply chain management in the electronics industry: An emerging economy case. International Journal of Logistics Research and Applications. https://doi.org/10.1080/13675567. 2020.1839029

Behl, A., \& Dutta, P. (2019). Humanitarian supply chain management: A thematic literature review and future directions of research. Annals of Operations Research, 283(1-2), 1001-1044. https://doi.org/10.1007/ s10479-018-2806-2 
Behl, A., Dutta, P., \& Gupta, S. (2019). Critical success factors for humanitarian supply chain management: A grey DEMATEL approach. IFAC-PapersOnLine, 52(13), 159-164. https://doi.org/10.1016/j.ifacol.2019. 11.169

Bhatia, M. S., \& Srivastava, R. K. (2018). Analysis of external barriers to remanufacturing using greyDEMATEL approach: An Indian perspective. Resources, Conservation and Recycling, 136(December), 79-87. https://doi.org/10.1016/j.resconrec.2018.03.021

Borowski, E., Cedillo, V. L., \& Stathopoulos, A. (2021). Transportation research interdisciplinary perspectives dueling emergencies : Flood evacuation ridesharing during the COVID-19 pandemic. Transportation Research Interdisciplinary Perspectives, 10(March), 100352. https://doi.org/10.1016/j.trip.2021.100352

Cao, Y., Li, Q., Chen, J., Guo, X., Miao, C., Yang, H., Chen, Z., \& Li, C. (2020). Hospital emergency management plan during the COVID-19 Epidemic. Academic Emergency Medicine, 27(4), 309-311. https://doi.org/10.1111/acem.13951

Celik, E., \& Taskin Gumus, A. (2016). An outranking approach based on interval type-2 fuzzy sets to evaluate preparedness and response ability of non-governmental humanitarian relief organizations. Computers and Industrial Engineering, 101, 21-34. https://doi.org/10.1016/j.cie.2016.08.020

Chan, D. W. K. (2020). A reflection on the anti-epidemic response of COVID-19 from the perspective of disaster management. International Journal of Nursing Sciences, 7(3), 382-385. https://doi.org/10.1016/j.ijnss. 2020.06.004

COVID-19 Map - Johns Hopkins Coronavirus Resource Center. (2021). Johns Hopkins University \& Medicine. Retrieved February, 2021from https://coronavirus.jhu.edu/map.html

Craft, R. C., \& Leake, C. (2002). The Pareto principle in organizational decision making. Management Decision, 40(8), 729-733. https://doi.org/10.1108/00251740210437699

Dalalah, D., Hayajneh, M., \& Batieha, F. (2011). A fuzzy multi-criteria decision making model for supplier selection. Expert Systems with Applications, 38(7), 8384-8391. https://doi.org/10.1016/j.eswa.2011. 01.031

Davis, I. (2014). Disaster risk management in Asia and the Pacific. In Disaster Risk Management in Asia and the Pacific. https://doi.org/10.4324/9781315761336

Ding, X. F., \& Liu, H. C. (2018). A 2-dimension uncertain linguistic DEMATEL method for identifying critical success factors in emergency management. Applied Soft Computing, 71, 386-395. https://doi. org/10.1016/j.asoc.2018.07.018

Dinter, B. (2013). Success factors for information logistics strategy-An empirical investigation. Decision Support Systems, 54(3), 1207-1218. https://doi.org/10.1016/j.dss.2012.09.001

Doan, X. V., \& Shaw, D. (2018). Resource allocation when planning for simultaneous disasters. European Journal of Operational Research, 274(2), 687-709. https://doi.org/10.1016/j.ejor.2018.10.015

Dubey, R., Bryde, D. J., Foropon, C., Graham, G., Giannakis, M., \& Mishra, D. B. (2020a). Agility in humanitarian supply chain: An organizational information processing perspective and relational view. Annals of Operations Research. https://doi.org/10.1007/s10479-020-03824-0

Dubey, R., Bryde, D. J., Foropon, C., Tiwari, M., Dwivedi, Y., \& Schiffling, S. (2021). An investigation of information alignment and collaboration as complements to supply chain agility in humanitarian supply chain. International Journal of Production Research, 59(5), 1586-1605. https://doi.org/10.1080/ 00207543.2020 .1865583

Dubey, R., Gunasekaran, A., Bryde, D. J., Yogesh, K., \& Papadopoulos, T. (2020b). Blockchain technology for enhancing swift-trust, collaboration and resilience within a humanitarian supply chain setting. International Journal of Production Research, 58(11), 3381-3398. https://doi.org/10.1080/00207543.2020. 1722860

Dubey, R., Gunasekaran, A., Childe, S. J., Roubaud, D., Fosso Wamba, S., Giannakis, M., \& Foropon, C. (2019a). Big data analytics and organizational culture as complements to swift trust and collaborative performance in the humanitarian supply chain. International Journal of Production Economics, 210, 120-136. https://doi.org/10.1016/j.ijpe.2019.01.023

Dubey, R., Gunasekaran, A., \& Papadopoulos, T. (2019b). Disaster relief operations: Past, present and future. Annals of Operations Research, 283(1), 1-8. https://doi.org/10.1007/s10479-019-03440-7

Ebrahim, S. H., Rahman, N. M. M., Imtiaz, R., Gozzer, E., Alqahtani, S. A., Ahmed, Y., \& Memish, Z. A. (2020). Forward planning for disaster-related mass gatherings amid COVID-19. The Lancet Planetary Health, 4(9), 379-380. https://doi.org/10.1016/S2542-5196(20)30175-3

Edjossan-Sossou, A. M., Galvez, D., Deck, O., Al Heib, M., Verdel, T., Dupont, L., Chery, O., Camargo, M., \& Morel, L. (2020). Sustainable risk management strategy selection using a fuzzy multi-criteria decision approach. International Journal of Disaster Risk Reduction, 45(January), 101474. https://doi. org/10.1016/j.ijdrr.2020.101474

Etikan, I., \& Bala, K. (2017). Sampling and sampling methods. Biometrics \& Biostatistics International Journal, 5(6), 5-7. https://doi.org/10.15406/bbij.2017.05.00149 
Fotopoulos, C., Kafetzopoulos, D., \& Gotzamani, K. (2011). Critical factors for effective implementation of the HACCP system: A Pareto analysis. British Food Journal, 113(5), 578-597. https://doi.org/10.1108/ 00070701111131700

Fuli, G., Foropon, C., \& Xin, M. (2020). Reducing carbon emissions in humanitarian supply chain: The role of decision making and coordination. Annals of Operations Research. https://doi.org/10.1007/s10479020-03671-Z

Gersons, B. P. R., Smid, G. E., Smit, A. S., Kazlauskas, E., \& McFarlane, A. (2020). Can a 'second disaster' during and after the COVID-19 pandemic be mitigated? European Journal of Psychotraumatology, 11(1), 2-5. https://doi.org/10.1080/20008198.2020.1815283

Gunessee, S., Subramanian, N., Roscoe, S., \& Ramanathan, J. (2018). The social preferences of local citizens and spontaneous volunteerism during disaster relief operations. International Journal of Production Research, 56(21), 6793-6808. https://doi.org/10.1080/00207543.2017.1414330

Han, Y., \& Deng, Y. (2018a). A hybrid intelligent model for assessment of critical success factors in highrisk emergency system. Journal of Ambient Intelligence and Humanized Computing, 9(6), 1933-1953. https://doi.org/10.1007/s12652-018-0882-4

Han, Y., \& Deng, Y. (2018b). An enhanced fuzzy evidential DEMATEL method with its application to identify critical success factors. Soft Computing, 22(15), 5073-5090. https://doi.org/10.1007/s00500-018-3311-X

Ishiwatari, M., Koike, T., Hiroki, K., Toda, T., \& Katsube, T. (2020). Managing disasters amid COVID-19 pandemic: Approaches of response to flood disasters. Progress in Disaster Science, 6(April), 100096. https://doi.org/10.1016/j.pdisas.2020.100096

Ivanov, D. (2020). Viable supply chain model: Integrating agility, resilience and sustainability perspectivesLessons from and thinking beyond the COVID-19 pandemic. Annals of Operations Research. https:// doi.org/10.1007/s10479-020-03640-6

Kaur, J., Sidhu, R., Awasthi, A., \& Srivastava, S. K. (2019). A Pareto investigation on critical barriers in green supply chain management. International JoUrnal of Management Science and Engineering Management, 14(2), 113-123. https://doi.org/10.1080/17509653.2018.1504237

Khoo, L. P., Tor, S. B., \& Zhai, L. Y. (1999). Rough-set-based approach for classification and rule induction. International Journal of Advanced Manufacturing Technology, 15(6), 438-444. https://doi.org/10.1007/ s001700050088

Li, Y., Hu, Y., Zhang, X., Deng, Y., \& Mahadevan, S. (2014). An evidential DEMATEL method to identify critical success factors in emergency management. Applied Soft Computing, 22, 504-510. https://doi. org/10.1016/j.asoc.2014.03.042

Lin, K. P., Tseng, M. L., \& Pai, P. F. (2018). Sustainable supply chain management using approximate fuzzy DEMATEL method. Resources, Conservation and Recycling, 128, 134-142. https://doi.org/10.1016/j. resconrec.2016.11.017

Liu, X., Wang, Z., Zhang, S., \& Liu, J. (2019). Analysis of influencing factors in emergency management based on an integrated methodology. Adaptive Behavior, 27(5), 331-345. https://doi.org/10.1177/ 1059712319858623

Liu, Z., \& Ming, X. (2019). A framework with revised rough-DEMATEL to capture and evaluate requirements for smart industrial product-service system of systems. International Journal of Production Research, 57(22), 7104-7122. https://doi.org/10.1080/00207543.2019.1577566

Mao, W., Wang, W., Luo, D., \& Sun, H. (2019). Analyzing interactions between risk factors for ice disaster in Ning-Meng reach of Yellow River based on grey rough DEMATEL method. Natural Hazards, 97(3), 1025-1049. https://doi.org/10.1007/s11069-019-03684-3

Meibodi, L. A., \& Monavvarian, A. (2010). Recognizing critical success factors (CSF) to achieve the strategic goals of SAIPA press. Business Strategy Series, 11(2), 124-133. https://doi.org/10.1108/ 17515631011026443

Modgil, S., Singh, R. K., \& Foropon, C. (2020). Quality management in humanitarian operations and disaster relief management: A review and future research directions. Annals of Operations Research. https://doi. org/10.1007/s10479-020-03695-5

Moktadir, M. A., Ali, S. M., Rajesh, R., \& Paul, S. K. (2018). Modeling the interrelationships among barriers to sustainable supply chain management in leather industry. Journal of Cleaner Production, 181, 631-651. https://doi.org/10.1016/j.jclepro.2018.01.245

Oloruntoba, R. (2010). An analysis of the Cyclone Larry emergency relief chain: Some key success factors. International Journal of Production Economics, 126(1), 85-101. https://doi.org/10.1016/j.ijpe.2009. 10.013

Pankow, K. L., Rusho, J., Pechmann, J. C., Hale, J. M., Whidden, K., Holt, J., Mesimeri, M., Wells, D., \& Koper, K. D. (2021). Responding to the 2020 Magna, Utah, Earthquake sequence during the COVID-19 pandemic shutdown. Seismological Society of America, 92(1), 6-16. https://doi.org/10.1785/0220200265 
Peters, K., \& Lovell, E. (2020). Reducing the risk of protracted and multiple disaster displacements in AsiaPacific (Issue May).

Phillips, C. A., Caldas, A., Cleetus, R., Dahl, K. A., Declet-Barreto, J., Licker, R., Merner, L. D., Ortiz-Partida, J. P., Phelan, A. L., Spanger-Siegfried, E., Talati, S., Trisos, C. H., \& Carlson, C. J. (2020). Compound climate risks in the COVID-19 pandemic. Nature Climate Change, 10(7), 586-588. https://doi.org/10. 1038/s41558-020-0804-2

Prager, F., Wei, D., \& Rose, A. (2016). Total economic consequences of an influenza outbreak in the United States. Risk Analysis, 37(1), 4-19. https://doi.org/10.1111/risa.12625

Queiroz, M. M., Ivanov, D., Dolgui, A., \& Fosso Wamba, S. (2020). Impacts of epidemic outbreaks on supply chains: Mapping a research agenda amid the COVID-19 pandemic through a structured literature review. Annals of Operations Research. https://doi.org/10.1007/s10479-020-03685-7

Rajesh, R., \& Ravi, V. (2015). Modeling enablers of supply chain risk mitigation in electronic supply chains: A Grey-DEMATEL approach. Computers and Industrial Engineering, 87, 126-139. https://doi.org/10. 1016/j.cie.2015.04.028

Rathnayake, D. K., Kularatne, D., \& Abeysinghe, S. (2020). Barriers and enablers of coastal disaster resilience-Lessons learned from tsunami in Sri Lanka. International Journal of Disaster Resilience in the Built Environment, 11(2), 275-288. https://doi.org/10.1108/IJDRBE-07-2019-0050

Rivera, J., Ceesay, A. A., \& Sillah, A. (2020). Challenges to disaster risk management in The Gambia: A preliminary investigation of the disaster management system's structure. Progress in Disaster Science, 6, 100075. https://doi.org/10.1016/j.pdisas.2020.100075

Rok, Ц , Markoti, A., \& Capak, K. (2020). Earthquake in the time of COVID-19: The story from Croatia (CroVID-20). Journal of Global Health, 10(1), 3-6. https://doi.org/10.7189/jogh.10.010349

Sakurai, M., \& Chughtai, H. (2020). Resilience against crises : COVID-19 and lessons from natural disasters. European Journal of Information Systems, 29(5), 585-594. https://doi.org/10.1080/0960085X. 2020.1814171

Salim, H. K., Stewart, R. A., Sahin, O., \& Dudley, M. (2019). End-of-life management of solar photovoltaic and battery energy storage systems: A stakeholder survey in Australia. Resources, Conservation and Recycling, 150(November), 104444. https://doi.org/10.1016/j.resconrec.2019.104444

Sardjono, W., Harisno Perdana, W. G., Pujadi, T., \& Iskandar, K. (2020). Critical success factor measurement model implementation of natural disaster mitigation knowledge management systems. AIP Conference Proceedings. Doi, 10(1063/5), 0006797.

Sasangohar, F., Moats, J., Mehta, R., \& Peres, S. C. (2020). Disaster ergonomics: Human factors in COVID19 pandemic emergency management. Human Factors, 62(7), 1061-1068. https://doi.org/10.1177/ 0018720820939428

Simonovic, S. P. (2021). Floods and the COVID-19 pandemic-A new double hazard problem. Wiley Interdisciplinary Reviews, 8(2), e1509. https://doi.org/10.1002/wat2.1509

Siriporananon, S., \& Visuthismajarn, P. (2018). Key success factors of disaster management policy: A case study of the Asian cities climate change resilience network in Hat Yai city, Thailand. Kasetsart Journal of Social Sciences, 39(2), 269-276. https://doi.org/10.1016/j.kjss.2018.01.005

Song, W., \& Cao, J. (2017). A rough DEMATEL-based approach for evaluating interaction between requirements of product-service system. Computers \& Industrial Engineering, 110, 353-363. https://doi.org/ 10.1016/j.cie.2017.06.020

Song, W., \& Sakao, T. (2018). An environmentally conscious PSS recommendation method based on users' vague ratings: A rough multi-criteria approach. Journal of Cleaner Production, 172, 1592-1606. https:// doi.org/10.1016/j.jclepro.2017.10.092

Su, Z., Zhang, G., Liu, Y., Yue, F., \& Jiang, J. (2016). Multiple emergency resource allocation for concurrent incidents in natural disasters. International Journal of Disaster Risk Reduction, 17, 199-212. https://doi. org/10.1016/j.ijdrr.2016.05.003

Talib, M. S. A., Hamid, A. B. A., \& Thoo, A. C. (2015). Critical success factors of supply chain management: A literature survey and Pareto analysis. EuroMed Journal of Business, 10(2), 234-263. https://doi.org/ 10.1108/EMJB-09-2014-0028

Venkatesh, V. G., Zhang, A., Luthra, S., Dubey, R., Subramanian, N., \& Mangla, S. (2017). Barriers to coastal shipping development: An Indian perspective. Transportation Research Part d: Transport and Environment, 52, 362-378. https://doi.org/10.1016/j.trd.2017.03.016

World Health Organization. (2019). Health Emergency and Disaster Risk Management: Overview. In Health Emergency and Disaster Risk Management Fact Sheets. https://www.who.int/hac/techguidance/ preparedness/health-emergency-and-disaster-risk-management-framework-eng

Worldometer. (2021). Bangladesh Coronavirus. Retrieved December, 2021 from https://www.worldometers. info/coronavirus/country/bangladesh/ 
Yadav, D. K., \& Barve, A. (2015). Analysis of critical success factors of humanitarian supply chain: An application of Interpretive Structural Modeling. International Journal of Disaster Risk Reduction, 12, 213-225. https://doi.org/10.1016/j.ijdrr.2015.01.008

Zhai, L. Y., Khoo, L. P., \& Zhong, Z. W. (2008). A rough set enhanced fuzzy approach to quality function deployment. International Journal of Advanced Manufacturing Technology, 37(5-6), 613-624. https:// doi.org/10.1007/s00170-007-0989-9

Zhai, L. Y., Khoo, L. P., \& Zhong, Z. W. (2009). Design concept evaluation in product development using rough sets and grey relation analysis. Expert Systems with Applications, 36(3), 7072-7079. https://doi. org/10.1016/j.eswa.2008.08.068

Zhou, Q., Huang, W., \& Zhang, Y. (2011). Identifying critical success factors in emergency management using a fuzzy DEMATEL method. Safety Science, 49(2), 243-252. https://doi.org/10.1016/j.ssci.2010.08.005

Zhou, X., Shi, Y., Deng, X., \& Deng, Y. (2017). D-DEMATEL: A new method to identify critical success factors in emergency management. Safety Science, 91, 93-104. https://doi.org/10.1016/j.ssci.2016.06.014

Publisher's Note Springer Nature remains neutral with regard to jurisdictional claims in published maps and institutional affiliations. 